\title{
5 INTRODUCCIÓN AL SECTOR DE LA SANIDAD EN CATALUNYA
}

\subsection{NOTAS HISTÓRICAS SOBRE LOS HOSPITALES EN CATALUNYA'}

Es necesario saber que las instituciones hospitalarias surgen, y se hacen necesarias, cuando la sociedad que las genera ha alcanzado un cierto grado de complejidad. Cada hospital adquiere un nombre y una fisonomía propia. Siempre existen cambios. Se hacen mayores, se desplazan, se unen entre sí, se extinguen o se diversifican.

Existen muchos estudios sobre algunos aspectos de los hospitales de Catalunya, sobre todo trabajos bien documentados referidos a un hospital concreto. Pero una visión panorámica de la evolución del hospital como una institución se hace difícil, porque la historia de cualquier hospital se encuentra entrelazada con su marco geográfico, cultural y económico.

Describiremos una breve historia evolutiva basada en los sucesivos modelos o conceptos doctrinales.

\subsubsection{EL HOSPITAL CRISTIANO [1000—1400]}

Durante muchos siglos los hospitales han sido instituciones exclusivamente eclesiásticas. Continuaba el espíritu del hospital cristiano, nacido en Bizancio, y que la rápida expansión del Cristianismo exportó por todo el mundo. El hospital medieval, entre los años 1000 y 1400, se organiza en medio de sorprendentes y poderosos acontecimientos.

1 Este epígrafe está basado en el artículo que escribió el Dr. Ignasi Aragó i Mitjans y que fue publicado en «La Xarxa Hospitalària d’Utilització Pública de Catalunya. Història d'una diversitat». Generalitat de Catalunya [1994, pp. 23-29]. 


\section{El hospital monástico}

Los benedictinos fijaron un modelo de hospital en las encrucijadas de los caminos. Configuran, describen y organizan los espacios esenciales de un establecimiento para viajeros y enfermos. De ellos son ejemplos Montecasino [529] y Saint Gall [820]. En Catalunya es en Poblet donde se ponen en práctica estas ideas.

\section{Hospicios de paso y hostales}

Tenían la función de alojar y cuidar los viajeros, protegerlos de las inclemencias del tiempo y auxiliarlos en sus dificultades. En Catalunya, existieron muchos. El de Vielha, bajo la protección de Sant Nicolau de los Pontells, se dice: «Cualquier viajero tiene derecho al agua, a la sal y al vinagre y a un sitio cerca del fuego, [859]». Se pueden destacar los de Benasc, el Coll de la Perxa, la Bonaigua [965], y el refugio de la Mare de Déu d'Ares, el de Sant Joan de l'Erm, o el de Santa Magdalena.

\section{Las peregrinaciones hasta Santiago de Compostela}

Iban peregrinos y enfermos de toda clase. A lo largo del camino son atendidos en hostales, leproserías, hospicios y hospitales. Surgen comunidades religiosas dedicadas a cuidarlos. En Catalunya, como muestra de este modelo, tiene diversos hospitales de Sant Jaume.

\section{Las cruzadas}

Durante dos siglos, las cruzadas movilizan miles de personas para rescatar la Tierra Santa de las manos de los infieles. Hubieron sanguinarias batallas con graves repercusiones políticas, militares, económicas y sanitarias. Ninguno de los objetivos previstos en las nueve cruzadas [de 1055 a 1271] se cumplieron. Dejaron temibles rastros de enfermedades, invalidez, injusticias y decepciones.

\section{Las ordenes militares y religiosas}

Nacidas dentro del clima arrasador de las cruzadas. Citaremos el Orden del Hospital de Sant Joan de Jerusalem, la de Sant Llàtzer y la de los Templos. En Catalunya, los Templos tuvieron más de ciento treinta establecimientos. Los Templos concretaron diversas actividades benéficas, militares y esotéricas —enigmáticas y reservadas a unos pocos-.

\section{Las epidemias}

La gente de edad mediana se veía repetidamente atacada por diversos flagelos. Los pobres de Catalunya y sus hospitales conservan referencias bien precisas de aquellas maldades. 


\section{El hospital episcopal}

El último modelo asistencial propio de aquella época, dentro del tejido de hospitales eclesiásticos, fue el hospital episcopal. Se construye adjunto a la sede o la iglesia principal. Hubieron en la Seu d'Urgell, Vic, Santes Creus y en la Canonja de Barcelona.

\subsubsection{EL HOSPITAL MEDIEVAL [1400—1500]}

El hospital medieval inicia a lo largo del siglo XV cambios importantes.

\section{La ascensión de la burguesía}

Las ciudades empiezan a crecer. Sirvientes y vasallos abandonan sus señores feudales y se integran en la ciudad con la gente del burgo - los burgueses - consiguiendo libertades y aprendiendo nuevos oficios. El hospital ya no es propiedad exclusiva de la Iglesia y se desvincula de monasterios y claustros catedralicios. Con todo, el obispo sigue velando por la atención espiritual.

\section{Las funciones del hospital}

El 17 de abril de 1401 es una data clave — cuatro piedras de cuatro hospitales barceloneses fueron llevadas en procesión para los fundamentos del Hospital de la Santa Creu—. También en Lleida, en 1445, siete hospitales menores se unieron en uno.

\section{El libro de las reglas}

El Hospital del Santo Espíritu, en Roma, redacta un libro trascendente. Viene a ser el primer tratado de administración hospitalaria. Define funciones, ordena normas y reglamentos. El «Liber Regulae Sancti Spiritus» [1227-1247] es una publicación sorprendentemente bien ilustrada. Su doctrina se expande por Europa y los conquistadores la transportan a las nuevas tierras de América. En Catalunya tiene las sucesivas y detalladas Ordenaciones del Hospital de la Santa Creu.

En resumen, los hospitales medievales cumplieron el mandato de practicar la caridad hacia los pobres y los enfermos. Ejercitaban las obras de misericordia, especialmente las espirituales. No podían curarlos médicamente, pero si que sabían atenderles y cuidarles. 
FIGURA 5.1. Ordenaciones del Hospital General de la Santa Creu de Barcelona, año 1707.

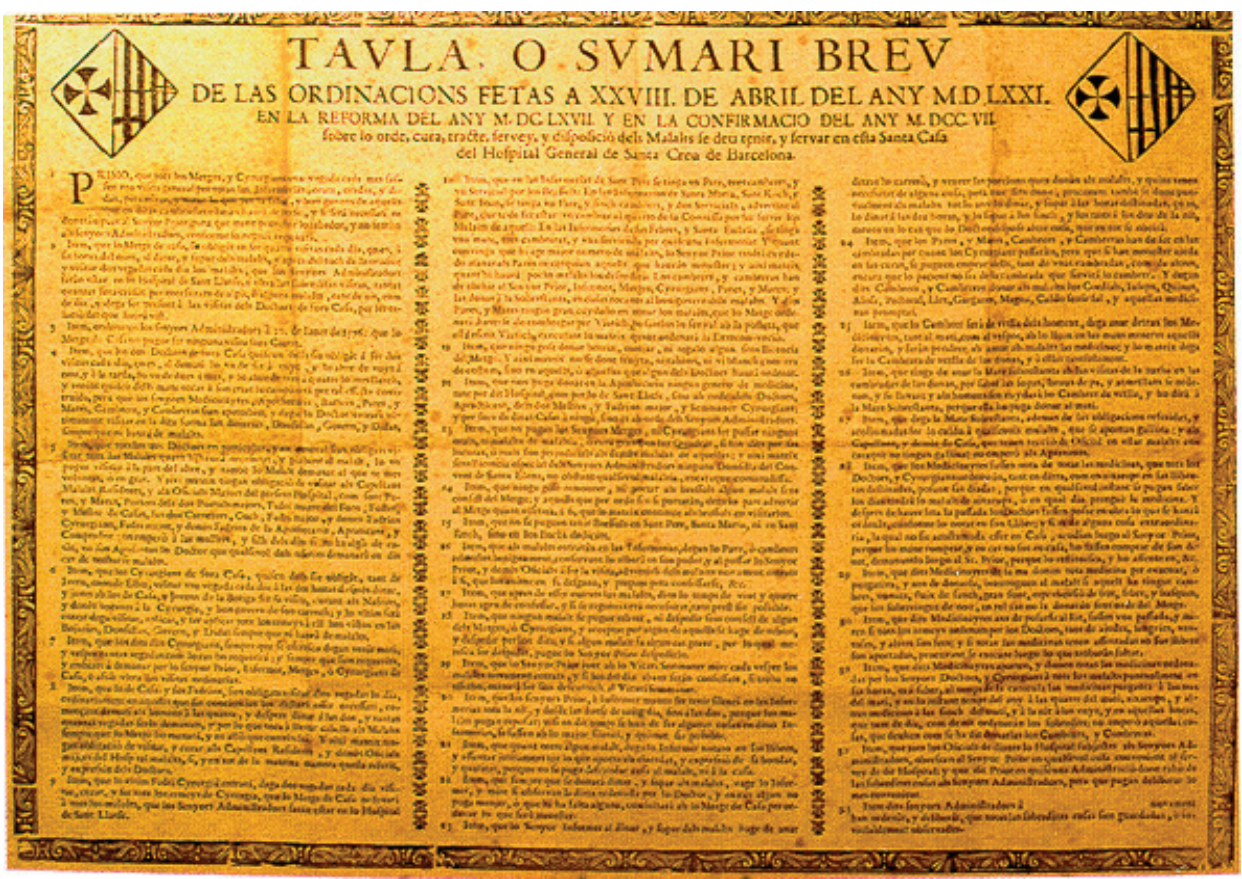

(C) La Xarxa Hospitalària d’Utilització Pública de Catalunya. Història d'una diversitat [1994, p. 24].

\subsubsection{HOSPITAL CIVIL [SIGLOS XV—XVII]}

\section{El renacimiento}

Durante la época medieval la cultura era teocéntrica. Dios era el centro de todo. El Renacimiento sitúa el hombre en el centro del Universo. Hay una explosión de fuerzas que parecían adormecidas y, como imagen de aquel gran cambio, Florencia pasa a ser un núcleo resplandeciente y deslumbrador. Los hospitales del Renacimiento en Italia se construyen como palacios. En España, los hospitales reales se sitúan dentro del estilo renacentista: El Hospital de los Reyes Católicos, en Santiago de Compostela [1501-1511]; El de Granada [1494-1550]; El de la Santa Cruz, en Toledo [1504-1515]; El Estudio de Salamanca [1540]; El de «Las Cinco Llagas», en Sevilla [1546] y El de Zamora [1517-1518]. En Catalunya el Hospital de la Santa Creu continua la tradición medieval. 


\section{La reforma protestante}

La explosión entusiasta y devastadora del Renacimiento continua con el proceso de rebelión religiosa de Luter — con la prioridad de la fe sobre las obras, con el rechazo de la remisión automática de los pecados por las buenas obrasEn el ámbito hospitalario, la reforma hace disminuir los legados en favor de las obras de caridad, mejora los recursos públicos y relaciona entre sí centros asistenciales civiles. El concilio de Trento, que duró 18 años [1545-1563], reforma la actitud conservadora de la Iglesia, pero transfiere, en gran parte, el control de los hospitales eclesiásticos al Estado.

\section{Los fundadores}

En continuación de las grandes ordenes monásticas de la edad media surgen, por toda Europa, fundaciones de comunidades de ayuda a los necesitados y a los hospitales. Entre más de trescientas obras, se puede citar las de Joan de Déu [1495-1550], Camil de Lel.lis [1550_1614], Vicenç de Paül [1580-1660] y Lluïsa de Marillac [1591 - 1660]. En Catalunya hubo una treintena de fundadores o fundadoras, especialmente Francesc Darder, médico cirujano del Hospital de la Santa Creu, de Barcelona, que hace donación de todos sus bienes por una causa benéfica, que en el año 1882 pasa a ser congregación religiosa, conocida con el nombre popular de las Darderes. A través de los fundadores, la Iglesia se hace presente por medio de las órdenes hospitalarias.

\subsubsection{LA REVOLUCIÓN FRANCESA}

La Revolución Francesa [1751-1797/1799—1815] acelera nuevos cambios, como la abolición de la Monarquía, el establecimiento de los principios de Libertad-Igualdad-Fraternidad y la Proclamación de los Derechos del Hombre. El incendio del Hôtel—Dieu, en París, produce una auténtica conmoción mental. El debate sobre el nuevo hospital fue como un banco de pruebas donde se discutieron muchas situaciones hospitalarias. La filosofía asistencial y la arquitectura hospitalaria se quedaron balanceadas del todo. Los enciclopedistas [1751 - 1772] establecen el racionalismo, el escepticismo, el empirismo y la tolerancia. Poco después, la noción de Caridad evoluciona hacia al concepto de Deber Social y se define el concepto de Utilidad Pública. El Abat de Saint Pierre introduce un nuevo termo, la Beneficencia: «Es la razón iluminada que inspira el deber de ayudar al prójimo». Es la caridad laica [1767]. En el año II del Mesidor [1794] se establece la disolución de las órdenes religiosas. Los monjes 
de los hospitales marchan, pero los malos resultados de las asistentas laicas substitutas hace que los dirigentes demanden que les monjes retornen a sus lugares, pero que no porten hábito y que las prácticas religiosas las hagan discretamente.

\subsubsection{LA MEDICINA CIENTÍFICA ENTRA EN EL HOSPITAL}

La medicalización de la asistencia hospitalaria empieza justo después de las limitaciones medievales. Se desvela poco a poco, superando la ignorancia y los prejuicios, el interés por el conocimiento del hombre y el conocimiento de la enfermedad. La historia del hospital es solo una parte de la historia de la medicina, como ésta es ahora una parte de la historia de la ciencia. La ciencia es un mundo que progresivamente se extiende y se hace complejo. En torno del año 1870 se produce, en muchos aspectos del saber, el fenómeno de la aceleración de la historia. Los ritmos de crecimiento de los conocimientos son excepcionalmente rápidos. En un mismo período de tiempo los descubrimientos y los conocimientos se interrelacionan entre sí. En Catalunya surgen y se reforman clínicas y hospitales nuevos al costado de los antiguos.

\section{La lucha contra la infección}

La lucha contra la infección empieza a ser el problema central de la actividad hospitalaria. Las grandes habitaciones llenas de camas, mal ventiladas, vibrantes de angustias, generan una terrible mortandad. Se establece una colaboración entre arquitectos e higienizadores y se precisan unos conjuntos de normas técnicas que rápidamente traspasan fronteras. Es la etapa del hospital pabellón. Pronto los avances de la bacteriología y la higiene neutralizan las ventajas del hospital pabellón y se llega a la conclusión que es mejor construir los hospitales en edificios monobloque, más compactos, en forma de letra H, L o Y. El concepto de hospital pabellón permitió la construcción de grandes conjuntos en los EEUU, Reino Unido y Francia, pero el mayor de Europa fue el Hospital General de Hamburgo con cerca de cien pabellones. En Catalunya los tres principales hospitales pabellón han sido los siguientes:

1. Institut Mental de la Santa Creu [1854-1892]. En el año 1854, la MIA —La Molt Il.lustre Administració de l'Hospital de la Santa Creu- encarga a Pi i Molist un estudio para un nuevo manicomio. Este viaja por Francia, Reino Unido, Bélgica, Alemania e Italia, y redacta un informe que es aprobado. Se encarga el proyecto al 
arquitecto Josep Oriol i Bernadet. El proyecto es frenado desde Madrid. En el año 1874, una real orden elogia el proyecto, pero no da el permiso de obras porque los establecimientos psiquiátricos habían de ser estatales. Finalmente después de muchas trabas administrativas, las obras empiezan en el año 1878, se terminan en el 1889 y el centro se inaugura en el año 1892, 38 años después del inicio de los estudios. El edificio se derrumba en el año 1972.

2. Hospital de la Santa Creu i Sant Pau [1898-1930]. La Exposición Universal de 1888 da un empujón a la gran ciudad. El Hospital de la Santa Creu se había quedado viejo y pequeño. Es bien conocida la imagen del cartel del pintor Llimona: «No hi ha llits!». Por otro lado, la facultad de Medicina se traslada a la calle de Casanova el año 1907. Era necesario construir un nuevo hospital. Con suerte llega el legado de Pau Gil y se encarga el proyecto a un arquitecto excepcional, Lluis Domènech i Montaner. Ahora, con una visión crítica, se puede decir que tanto el concepto como la arquitectura del Hospital de la Santa Creu i Sant Pau eran desfasados con el que preconizaban las políticas asistenciales de América y de Europa. Se tiene la suerte que Domènech i Montaner consigue un conjunto y unos detalles de una espléndida obra modernista. Con gran esfuerzo, lentamente y gradualmente se fue construyendo el hospital. Se puede sacar una enseñanza buena - los hombres son más importantes que las piedras-. Poner en funcionamiento algunos de los 46 pabellones que preveía el proyecto fue posible por la constante ayuda y participación de la sociedad civil y de los sus estamentos.

3. Hospital del Mar [1914-1994]. La lucha contra la infección es siempre presente en la historia del hospital. El municipio de Barcelona continua la acción benéfica de la Pia Almoina, asumiendo tareas cada vez más complejas. El primitivo dispensario de Can Tunis [1888] evoluciona hacia el Hospital de infecciosos [1914 - 1930], adoptando - justificadamente - la estructura de pabellón. En la lucha contra las epidemias, el municipio se hace cargo de arriesgadas responsabilidades — peste bubónica, fiebre amarilla o gripe, que afectó seriamente la ciudad de Barcelona durante el siglo pasadoDurante la guerra de 1936-1939, en el Hospital había de todo - tétanos, rabia, tuberculosis, meningitis, y un pabellón lleno de portadores de sarna—. Las epidemias continúan — 1939/40, varicela; 
1940/41, tifus exantemático; 1950, poliomielitis; 1971, cólera-. El Hospital Municipal del Mar es una pieza esencial en la historia de los hospitales de Catalunya. También evolucionó constantemente en nuevos campos —unidad de curas intensivas, 1970; Urgencias, 1978; servicios para toxicómanos/SIDA, 1981/1990, y después, el gran hospital olímpico-.

\subsubsection{LA MIGRACIÓN POLÍTICA, SANITARIA Y LA DIVERSIDAD HOSPITALARIA DE CATALUNYA}

Durante más de trescientos años, en Catalunya, había un solo hospital importante, el Hospital de la Santa Creu. En el año 1915, la Mancomunidad de Prat de la Riba impulsa grandes mejorías. Un nuevo edificio para la Maternidad y una red de hospitales que comarcalizan la asistencia. En abril de 1931, la Generalitat solicita al Sindicato de Médicos la redacción de unas ponencias sobre sanidad y hospitales. En el año 1933, cuando se hace el traspaso de poderes a la Generalitat, la organización será pensada según las posibilidades y necesidades de Catalunya, sabiendo que el país es formado por comarcas y no por provincias. La evolución de los hospitales en Catalunya fue diferente de la del resto de España, por la ausencia de hospitales públicos. Como compensación, casi todas las comarcas tienen sus fundaciones hospitalarias. El decreto de 1899 sobre desamortización de las fundaciones benéficas hace que, durante más de 120 años, los dineros de los hospitales benéficos quedasen «empapelados» en emisiones obligatorias de Títulos de Divida Pública Interior, al 3 o al 4\%. Después del año 1939, estos pequeños hospitales se quedan, descapitalizados, en situación de hospitales de pobres. En el año 1957, el Colegio de Médicos de Barcelona envía un cuestionario a los directores de hospitales. Las respuestas dibujan abundantes elementos negativos.

Entretanto se introducía progresivamente el Seguro Obligatorio de Enfermedad — SOE—. En el año 1969, por iniciativa de Josep Maria de Muller, presidente de la Diputación, se redacta el Plan General de Regionalización Hospitalaria de Catalunya y Baleares, el primer que se hace en España. Siguen otros estudios complementarios de calidad. Finalmente, la decisión de hacer el Mapa Sanitario, en 15 de enero de 1979, es el punto de arrancada hacia la actualidad. 


\subsection{ANTECEDENTES HISTÓRICOS}

Con la reinstauración de la Generalitat de Catalunya, en el año 1931, se inicia un proceso muy importante y de gran trascendencia, que tiene como objetivo intentar estructurar la sanidad catalana.

El Consejero de Sanidad y Beneficencia, encarga, en el año 1931, al Sindicato de Médicos de Catalunya, el estudio y las propuestas sectoriales de toda la sanidad catalana, incluyendo proyectos referentes a la Seguridad Social. En el mes de junio de 1931, una encuesta sobre los hospitales subvencionados y/o contratados y el estudio sobre los seguros sociales, fueron el importante punto de partida para configurar la ordenación hospitalaria y toda la sanidad catalana. Finalmente, el Parlament de Catalunya aprobó la Ley de Bases para la organización de los servicios de sanidad y asistencia social en Catalunya, que fue la Ley del 30 de marzo de 1934. Por primera vez se habla de servicios sanitarios mínimos y se fijan criterios para la ordenación territorial de la sanidad y de los hospitales.

Después de la guerra civil viene el fin de la Generalitat y ya no se habla de cuestiones sanitarias desde una perspectiva catalana. Todavía la Academia de Ciencias Médicas de Catalunya y Baleares sobrevive con gran dificultad y sirve de centro de las iniciativas aisladas en el campo de la sanidad y de la salud pública.

En 1964 un grupo de médicos crea el Centre Tècnic d'Estudis Hospitalaris, que es el primer equipo que se conoce que empezó a hacer estudios en el campo de la sanidad y de los hospitales en toda Catalunya.

En 1969 se elabora el Plan de Regionalización Hospitalaria de la 5 Región - Catalunya y Baleares - este estudio es el punto de partida, un año más tarde se elabora otro estudio que plantea una reorganización sanitaria y la propuesta de creación de un Servicio Nacional de Salud de Catalunya. Y lo siguen a partir de entonces varios otros.

La Conferencia Internacional sobre Atención Primaria de la Salud promovida por la OMS en 1978, reiteró que los gobiernos están obligados a tener en cuenta la salud de sus pueblos, obligación por la cuál solamente se puede cumplir por medio de la adopción de medidas sanitarias y sociales adecuadas y equitativamente distribuidas.

La atención primaria de la salud, como parte del sistema nacional de asistencia sanitaria completa, representa un gran avance en el camino de las conquistas de los objetivos sanitarios y sociales fundamentales. Cada país tendrá que interpretar y adoptar aspectos determinados y concretos sobre la atención primaria de la salud en función de su propio contexto social, político y de desarrollo. Todas las 
personas tienen el derecho y el deber de participar individualmente y colectivamente en la planificación y organización de su asistencia sanitaria.

La Conferencia apuntó la necesidad de una distribución equilibrada de todos los recursos disponibles, y particularmente de los recursos públicos, de manera que se preste una atención conveniente a los grupos de poblaciones más débiles desde el punto de vista de atención primaria de salud y desarrollo en general.

Las políticas nacionales de desarrollo en materia de salud tienen que ser accesibles a todos, con carácter prioritario, la atención primaria de salud como parte integrante de un sistema de asistencia sanitaria, teniendo en cuenta las características geográficas, sociales, culturales, políticas, económicas y otras del país del cuál se trata.

\subsection{EL MAPA SANITARI DE CATALUNYA}

El decreto del 7 de enero de 1980 —DOGC 7/3/80 — por el cuál se aprueba el Mapa Sanitari de Catalunya, fue el primer intento de planificación de la asistencia sanitaria en Catalunya después que la Guerra Civil Española trunca la «Ley de Bases para la organización del Servicio de Sanidad y Asistencia Social de Catalunya» que fue aprobada por el Parlamento Catalán en 30 de marzo de 1934 [Ruiz, 1997, p. 5].

El Mapa Sanitari de Catalunya «MS—80» recoge un inventario muy completo de los recursos físicos y personales referentes a los campos de la asistencia primaria, asistencia hospitalaria, sanidad veterinaria, sanidad farmacéutica y aspectos sanitarios del medio ambiente. En segundo lugar, también aportó un análisis de la realidad sanitaria de Catalunya desde una perspectiva sanitaria integral y no solo asistencial, indicando los recursos deseables y, también hacia una territorialidad sanitaria. Algunos sectores acusaron de no ser verdaderamente un Plan Sanitario, ya que no señalaba objetivos y no marcaba métodos, no asignaba recursos. Se tiene que considerar el MS - 80 como un buen marco de referencia y el punto de partida del actual Sistema Sanitario de Catalunya.

\subsubsection{DESPLIEGUE DEL MAPA SANITARIO}

El Departament de Sanitat i Seguretat Social elaboró el Desplegament del Mapa Sanitari de Catalunya-83, con el cuál se pretendió actualizar los criterios y la dotación previstos en el Mapa Sanitari, incorporando el sentido generalizado en los países occidentales sobre contención del gasto sanitario. Así, con la dotación 
hospitalaria propuesta por el MS-80 de 4 a 5 camas por 1.000 habitantes, se pasa a una propuesta del DMS -83 de 2,9 a 3,2 camas por 1.000 habitantes [Ruiz, 1997, p. 6].

FIGURA 5.2. Mapa del primer plan de regionalización sanitaria basado en la estructura comarcal, año 1933.

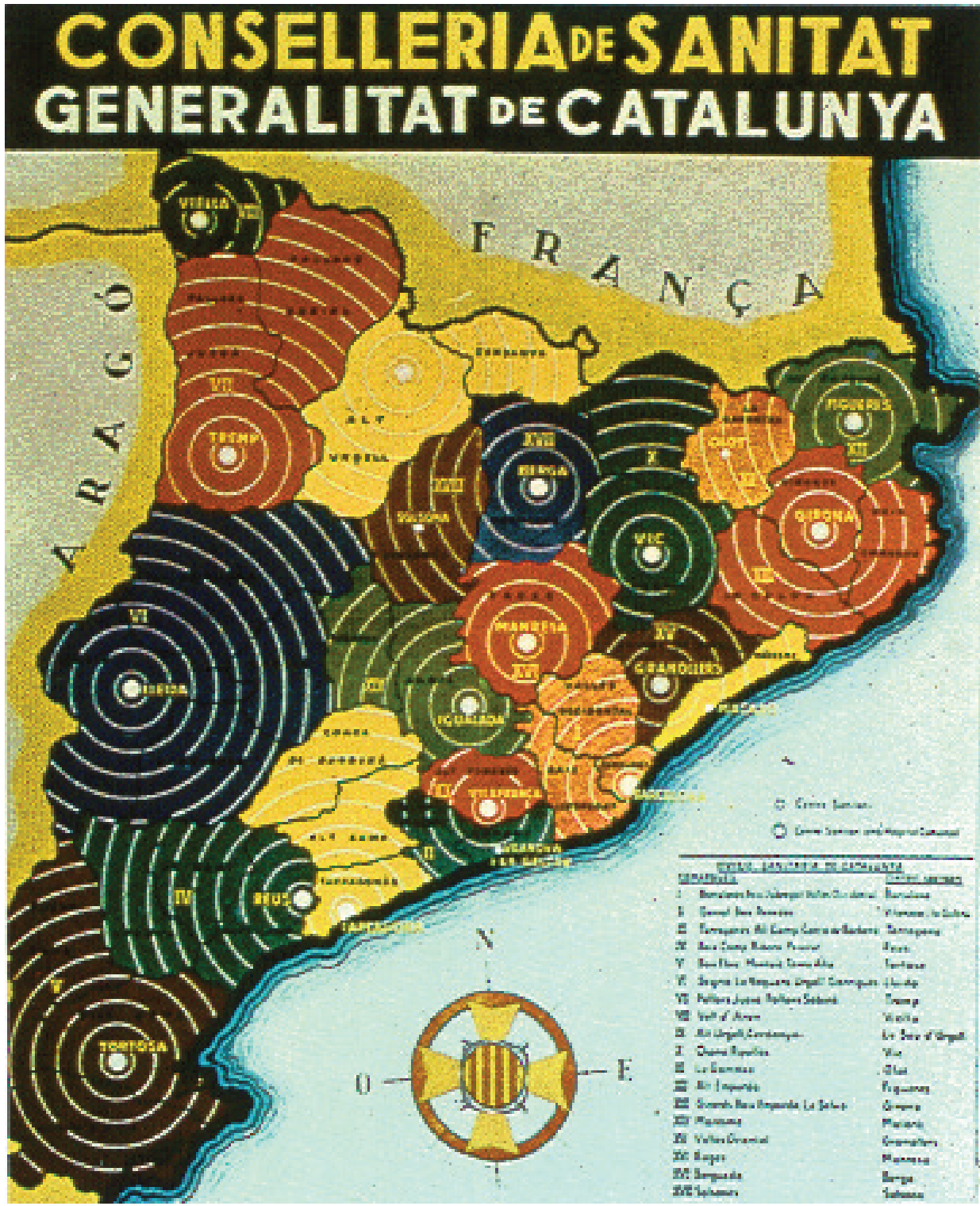

(C) La xarxa hospitàlaria d'utilització pública de Catalunya. Història d’una diversitat [1994, p. 28]. 
También se incorporan orientaciones sobre la capacidad óptima de los centros, su dimensión, rendimiento de las plantillas, objetivos de frecuentación, estancia media, etc.

De esta manera se establecía la planificación de la Asistencia Sanitaria Pública en Catalunya para los diez años posteriores a su elaboración.

Como objetivos básicos del DMS—83 se pueden destacar²:

1. Creación de la red hospitalaria de utilización pública —XHUP—, en un intento de racionalización de los recursos existentes y de coordinarlos dentro de la gran dispersión de competencia que había. Los puntos básicos para hacer la propuesta de hospitales necesarios para la XHUP partieron de la siguiente hipótesis para el 1992:

1.1 Frecuentación $=100-110$ por 1.000 habitantes.

1.2. Población $=6.000 .000$ habitantes.

1.3. Utilización de la SS $=90 \%$.

2. Dar prioridad a la asistencia primaria, y coordinarla eficazmente con la hospitalaria.

—El DMS - 83 propulsaba la integración funcional de los especialistas de la asistencia primaria en los centros de la XHUP-.

3. Mejoría de la eficiencia a través de tres propuestas:

3.1. Reducción de las estancias, especialmente de la estancia media.

3.2. Incremento de la tasa de ocupación.

3.3. Marcar objetivos de productividad del personal.

4. Mejorar la calidad asistencial. La acreditación hospitalaria garantizaría la calidad de la estructura del centro y el DMS - 83 propulsaba completarla con unos mecanismos que garantizasen la calidad del proceso asistencial. La propuesta era crear un programa de control de calidad que tuviese en cuenta:

4.1. Comisiones de control de calidad.

4.2. Circuito de información.

4.3. Formación continuada.

4.4. Difusión de las técnicas de control de calidad.

5. Descentralización geográfica facilitando el acceso físico de los usuarios al hospital. Uno de los problemas principales era - $\mathrm{y}$ continua siendo- la concentración de camas hospitalarias en

2 Siguiendo a Ruiz [1997, p. 6]. 
Barcelona, que propiciaba que 150.000 enfermos de fuera de Barcelona fuesen atendidos en esta ciudad.

6. Reequilibrio de los niveles asistenciales a través de la potenciación de los centros de nivel básico.

7. Fusión de hospitales para evitar duplicidades de servicios entre centros prójimos, que levan a una competitividad que incrementa los costes sin ir acompañada de una mejoría en la calidad asistencial. Poder compartir entre diferentes centros generales próximos para poder bajar los costes.

\subsection{PLAN DE REORDENACIÓN HOSPITALARIA DE CATALUNYA}

La transferencia de los servicios de la Seguridad Social en Catalunya para la Generalitat fue dentro del segundo semestre del 1981. El INSALUD transfiere sus centros propios.

Por otro lado la mayor parte de los centros concertados presentaban un importante endeudamiento, consecuencia de la congelación de tarifas con el INSALUD, y una situación de descapitalización progresiva que les había impedido de invertir en mantenimiento y en renovación de los equipamientos.

En 21 de diciembre de 1981 se publicaron las Ordenes de Concertación y Acreditación de Hospitales de 20 y 21 de noviembre de 1981. Esta Orden de Concertación pretendía adecuar las tarifas a los costes hospitalarios -incremento de tarifas-.

El efecto inmediato fue la mejoría de la situación financiera de los centros concertados, que sin poder eliminar su déficit acumulado, se lanzan hacia al objetivo histórico de expansión, fundamentalmente en personal, para dar cumplimento a las normas de acreditación y por el desarrollo de nuevas especialidades y técnicas. Eso produce un importante aumento de los costes hospitalarios, así como de la oferta asistencial que determinó un aumento notable de la demanda, con un crecimiento, aquellos años, en la tasa de facturación al Institut Català de la Salut _-ICS — superior al 20\% anual.

Este incremento necesario en los gastos sanitarios de los hospitales concertados, juntamente con un importante aumento progresivo en los costes de los hospitales propios, determinó que el ICS no pudiese hacer frente al elevado coste hospitalario generado y decidiese adoptar como medida de contención del gasto la congelación de las tarifas de 1983 durante dos años, 1984 y 1985. 
Porcausa de la crisis financiera en que seencontraran elICSy, consecuentemente, todo el sector que dependía de él, la Direcció General de Ordenació i Planificació Sanitària de la Conselleria de Sanitat i Seguretat Social de la Generalitat _DGOPS - presentó en el Parlament Català un Plan de Reordenación Hospitalaria — PRH — que adaptaba todo el marco de la planificación hospitalaria establecido en el DMS — 83, a los condicionantes de las previsiones presupuestarias y de las pérdidas acumuladas en el sector.

Este Plan, que fue elaborado con la participación de todas las partes implicadas en la su ejecución -Administración, sector hospitalario público y privado y sindicatos-, pretendía conseguir, en un período de cinco años y para todos los centros integrados en la XHUP, el equilibrio económico que permitiese asegurar la supervivencia de estos y el cumplimento de todas sus obligaciones fiscales y parafiscales; pero que, también, permitiese conseguir el equilibrio presupuestario del ICS y para eso los hospitales concertados tendrían que adaptar su cuenta de ingresos hasta el limite de la capacidad financiera de aquel.

Así, el PRH se convierte en el marco básico de planificación operativa para los hospitales, hasta su finalización en 1991.

El PRH pone un especial énfasis en la mejoría de la eficiencia —máxima eficiencia al menor coste- de los hospitales, la reducción de la estancia media de los pacientes y el aumento de su rotación, pero también, en conseguir una perfecta coordinación entre todos los hospitales que permite dimensionar óptimamente todos los recursos sanitarios en función de su área de influencia.

Pretendía evitar servicios hospitalarios duplicados de manera innecesaria, con una gran competencia entre ellos, y que no siempre sirven para mejorar la calidad, pero que incrementan el coste.

Con esta finalidad, una de las fórmulas que propulsaba era la coordinación o la integración de los hospitales excesivamente pequeños, poco rentables y con dificultades para el mantenimiento del nivel asistencial ahora exigido, por medio de la gestión conjunta de varios hospitales. De esta manera, el tamaño óptimo de un hospital en relación con su área de influencia, no sería siempre conseguida a través de un edificio mayor, y sí por la agrupación y coordinación funcional de varios hospitales.

Esa coordinación hospitalaria, que dependería en cada caso de su situación jurídica y económica, pudiendo ir desde la simple coordinación funcional, pasando por la mancomunidad de servicios, hasta la integración patrimonial.

Esta coordinación afectaría también, a los profesionales de los diferentes hospitales con tal de garantizar la formación continuada y el establecimiento de 
protocolos estandarizados que asegurasen la calidad asistencial en toda el área sanitaria, con independencia del hospital utilizado.

El PRH preveía el desarrollo de una red de hospitales y centros sociosanitarios para enfermos crónicos o que necesitan de un internamiento prolongado, que había de estar íntimamente coordinada con la de pacientes agudos.

La creación de esta red para enfermos crónicos permitió optimizar la de pacientes agudos, habiendo conseguido una disminución de la estancia media y aumentar el índice de rotación — enfermo/cama— ya que, a través de ésta, se pretendía evitar el prolongamiento de estancias por motivos sociales o de otra clase, no ligados al proceso patológico que motivaba el ingreso en el hospital por los enfermos agudos.

\subsection{LA RED HOSPITALARIA DE UTILIZACIÓN PÚBLICA}

La planificación hospitalaria del DMS—83 se basa en la constitución de la red hospitalaria de utilización pública -XHUP: Xarxa Hospitalària d’Utilització Pública—, que fue creada por el Decreto 202/1985 del 15 de julio.

Por medio de esta red se cubre la asistencia hospitalaria en la totalidad de la población protegida entonces por el sistema público de la Seguridad Social — $93 \%$ de la población-.

Esta red está integrada por los hospitales propios de la Seguridad Social y por los hospitales públicos o privados concertados con ésta para atender a sus beneficiarios.

El objetivo de la red es conseguir una homogeneidad asistencial que permita que todo el beneficiario de la Seguridad Social reciba una asistencia de calidad y con un coste mínimo, independientemente del lugar que viva en Catalunya.

Los hospitales concertados existen en todo el Estado español, siendo una fórmula para complementar los servicios propios de la Seguridad Social.

En Catalunya, con una importante tradición y dotación hospitalaria —hospitales municipales, de la Diputación, de la Iglesia, de fundaciones privadas sin ánimo de lucro—, la situación era muy diferente. Los hospitales del INSALUD, que representaban un 25\% de las camas para enfermos agudos que existían en Catalunya, lo que hacían en realidad eran complementar la red de concertados.

En el año 1981, solamente una cuarta parte de los ingresos hospitalarios cubiertos por la Seguridad Social fueran atendidos en centros propios de ésta, proporción inversa en el resto del Estado español, donde los hospitales propios atienden, aproximadamente, el 60\% de los beneficiarios. 
Los hospitales, para poder estar integrados en la XHUP, se hace imprescindible que, entre otros requisitos, cumplan la normativa establecida en el orden de acreditación del 21 de noviembre de 1981.

Esta Orden determina las condiciones mínimas obligatorias que, cuanto a equipamientos, organización, instalaciones y seguridad, han de cumplir los hospitales con tal de garantizar un nivel determinado de calidad en el desarrollo de su actividad.

Se trata de un análisis de la estructura del centro que pretende, básicamente, mejorar la calidad asistencial por medio de un control de calidad externo al propio centro —en el momento de su publicación, fue negada la acreditación a 43 centros hospitalarios que no cumplían los mínimos exigidos-.

Posteriormente, el Orden del 24 de abril de 1986 sobre regulación de los procedimientos para la integración y la exclusión de la XHUP —DOGC 5/7/86 - determina que a todos los hospitales de esta red de asistencia pública han de desarrollar seis tipos de actuación — compatibilidad analítica, indicadores de gestión, hoja de alta, control de calidad, auditoria compatible y plan de empresa-.

El resto de los hospitales no integrados dentro de esta red pueden optar por la atención a los enfermos crónicos o bien, limitar su oferta al libre mercado —asistencia privada-

Dentro de la XHUP, el Orden del 23 de abril de 1986 modifica los cuatro niveles de clasificación en que se dividen los hospitales catalanes — cinco si se tiene en cuenta el nivel 3 Monográfico_-, según el que establece el DMS—83, pasando a clasificarse en tres niveles, en función de las necesidades que han de cubrir, el tipo de asistencia que han de estar capacitados para prestar, el volumen de población que los justifica y el número máximo de camas que, para cada nivel, dispondrá la XHUP.

Por último el Decreto 179/1997 de 22 de julio $^{3}$ establece las modalidades de pago que rige la contratación de los servicios sanitarios en el ámbito del Servei Català de la Salut. Los centros sanitarios, atendiendo a su nivel de complejidad estructural, se clasifican en 4 grupos a seguir:

1. Grupo 1: Hospital General Básico Aislado y Hospital Complementario.

2. Grupo 2: Hospital General Básico contará con la tecnología asistencial necesaria para atender el $80 \%$ de la demanda hospitalaria de su área

3 Siguiendo el Decreto 179/1997 de 22 de julio publicado en el DOGC núm. 2445 de 31.07.1997 p. 8720 . 
de influencia y que se considera como una patología que no necesita de una gran dotación de personal y tampoco de equipamientos sofisticados; se situaron en la mayoría de las comarcas catalanas, cerca de las poblaciones a las cuales asisten.

3. Grupo 3: Hospital de Referencia, dará atención a la patología básica de su área —actuando como Hospital General Básico dentro de su núcleo de influencia- y cubrirá patología de nivel medio - que necesita de un cierto nivel de tecnología y de especialización- de toda su área de referencia, que cubrirá unos 400.000 habitantes.

4. Grupo 4: Hospital General de Alta Tecnología ${ }^{4}$, donde será atendida toda aquella patología que necesite de una alta especialización y una tecnología compleja —-10 hospitales en Catalunya-; al mismo tiempo que actuará como Hospital General Básico y de Referencia para sus zonas de influencia.

\subsection{INTRODUCCIÓN A LA LLEI D'ORDENACIÓ SANITÀRIA DE CATALUNYA}

El Proyecto de Llei d'Ordenació Sanitària de Catalunya — LOSC— responde a una necesidad de regular todas las acciones que permiten hacer efectivo el derecho a la protección de la salud de la población en Catalunya, y también para cumplir con el mandato contenido en la Ley General de Sanidad - LGSdictada al amparo del artículo 149.1.16 de la Constitución Española.

Este mandado establece un sistema plural que prevé el establecimiento de un servicio de salud en el ámbito de cada comunidad autónoma, configurado por todos los centros, servicios y establecimientos de la propia comunidad, las diputaciones, los ayuntamientos y cualquiera otras administraciones territoriales intracomunitarias.

El sistema sanitario catalán presenta, dentro del conjunto del Estado Español, una serie de peculiaridades que le hacen sensiblemente diferente.

El modelo del Servei Català de la Salut — SCS_ que se ha diseñado permite ejercer las responsabilidades que legalmente le corresponden en materia sanitaria, de acuerdo con las peculiaridades propias del sistema sanitario catalán y, al mismo tiempo, dando cumplimiento a los preceptos básicos de la LGS.

4 Dentro de la XHUP los Hospitales del Grupo 4 - Hospitales de alta tecnología — serán los estudiados en el marco de la tesis. 
Las acciones tomadas en el momento de los traspasos fueron encaminadas a ordenar los servicios sanitarios de acuerdo con su especial configuración. De esa manera, el Orden de Regulación de la Acción Concertada — 20 de noviembre de 1981 — y el Orden de Acreditación de Centros — 21 de noviembre de 1981_ fueron herramientas empleadas para conseguir y garantizar una correcta y homologable cualidad entre los diferentes centros, al mismo tiempo que una equidad en la distribución de recursos.

La Ley 12/1983, crea el Institut Català de la Salut _-ICS_ como entidad gestora de los servicios y de las prestaciones sanitarias propias de la Generalitat y de las transferidas de la Seguridad Social, se introduce, de esa manera y por primera vez en el sistema sanitario catalán los conceptos de planificación y gestión.

FIGURA 5.3. Desarrollo del modelo sanitario.
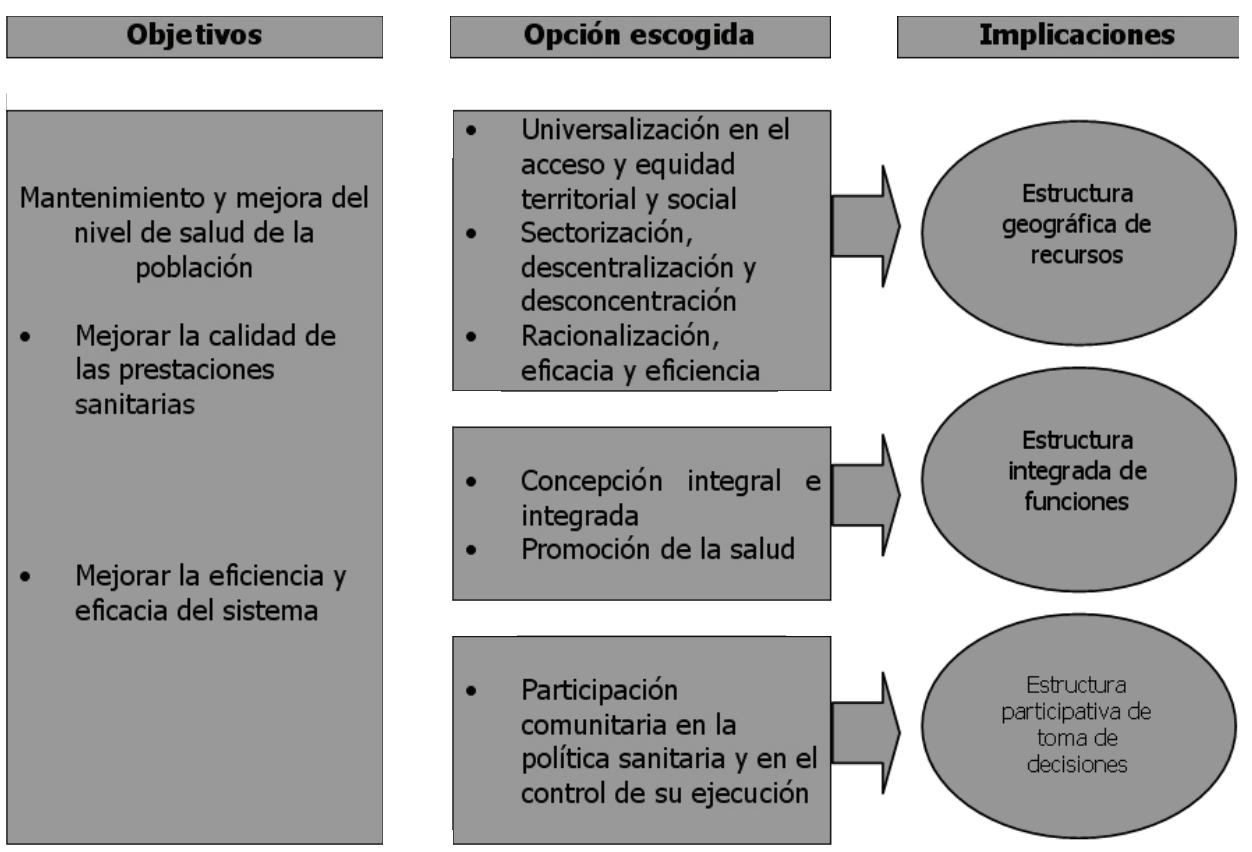

(C) McKinsey \& Company [1992, p. 2].

También se creó la figura del gerente como profesional del sistema sanitario, y se divide territorialmente el ICS en áreas de gestión, se inicia una política de descentralización, se ordena y racionaliza el sistema de concertación reduciendo los 21 niveles asistenciales existentes hasta el momento a 4 niveles asistenciales. 
A partir del Mapa Sanitari de Catalunya -MSC_, elaborado por el Departament de Sanitat i Assistència Social de la Generalitat, en 1980, se inició, el año 1983, los trabajos de Despliegue del Mapa Sanitari —DMS—, un plan estratégico que contenía ya los principios de la mayor parte de las reformas realizadas posteriormente, sobre todo en materia de atención primaria de salud y también de atención hospitalaria.

Las previsiones contenidas en el terreno hospitalario se implantaron, fundamentalmente, a través de la creación de la Red Hospitalaria de Utilización Pública - XHUP—, en el año 1985. Este Decreto tenía como objetivo principal conseguiruna ordenación hospitalaria quepermitiesela adecuada homogeneización de las prestaciones asistenciales, y también la utilización óptima de los recursos humanos y materiales.

Por otro lado, el DMS proporcionó la creación de diversos programas sectoriales como fórmula de planificación y programación en los diferentes ámbitos asistenciales.

De acuerdo con el contenido del Decreto 84/1985, de 21 de marzo, en el año 1985-86 se inicia la puesta en marcha de la reforma de la atención primaria de la salud.

Se creó en Catalunya una red de hospitales comarcales a partir del seguimiento de las previsiones del DMS, la aplicación del modelo diseñado de la XHUP, el Plan de Reordenación Hospitalaria — PRH— y la constitución de los consorcios hospitalarios. El mantenimiento de la XHUP como modelo de desarrollo de la política hospitalaria del SCS permitió un reequilibrio hospitalario del territorio. El objetivo era crear una red hospitalaria compacta, capaz de ejecutar la política sanitaria del Departament de Sanitat para tratar por igual todos los beneficiarios y trabajadores del sistema sanitario y seguir la tradición hospitalaria catalana, es decir, ser capaz de aprovechar todos los recursos existentes: Seguridad Social; Ayuntamientos; Fundaciones; Iglesia; Cruz Roja; Entidades mutualistas, etc.

\subsubsection{EL OBJETIVO DE LA LOSC}

La Organización Mundial de la Salud —OMS— estableció una estrategia que, con el titulo de «Salud para todos en el año 2000», habría de conducir las políticas sanitarias a la mejoría de la salud de la población.

El SCS tiene como misión, y de acuerdo con los objetivos que la OMS plantea para el año 2000, ser una herramienta que ayude a mejorar el nivel de salud de la población. 
Estos objetivos también comprenden la aparición de los nuevos retos en el futuro, como son las nuevas patologías, entre las cuales se destaca la lucha contra el Síndrome de la Inmune Deficiencia Adquirida —SIDA—, el envejecimiento de la población, que ha hecho necesario la creación de programes específicos para la $3^{a}$ edad y la alta tecnología.

El plan de la OMS «Salud para todos en el año 2000» está compuesto de 38 objetivos sanitarios, que habrán de ser asumidos por los gobiernos de los distintos países y por el SCS. Estos objetivos se poden resumir en 5 grandes grupos ${ }^{5}$ :

1. Conseguir una igualdad de acceso al sistema sanitario por parte de toda la población, es decir, la equidad y la igualdad de acceso. Este objetivo queda determinado, de un lado, por la universalización de las prestaciones. En este sentido, y a efectos de desarrollar el Real Decreto 1088/89, de 8 de septiembre, que despliega la LGS, el Consell Executiu de la Generalitat promulga el Decreto 55/1990, del 5 de marzo, que regula la extensión de la cobertura de la asistencia sanitaria de la Seguridad Social a las personas sin recursos económicos. Por medio de la Orden del 25 de abril de 1990, se desarrolla el proceso de extensión de la asistencia, que se completa en el año 1991.

2. Pasar a la población un concepto positivo de salud y hacer saber a todos que lo mejor es mantener la salud y no haber de tratar la enfermedad. Esto quiere decir, evidentemente, una potenciación de la promoción de la salud y de la prevención de la enfermedad.

3. Hacer realidad que la salud es cosa de todos y, en consecuencia, que todos tienen que participar, tal como se ha dicho en la OMS tantas veces. Se tiene que conseguir que en todos los programas preventivos y de promoción de la salud se impliquen no solamente los médicos y los profesionales sanitarios, sino, también los educadores, otros profesionales, los políticos y los propios padres.

4. Es necesario una cooperación multisectorial para que se produzcan las condiciones favorables para que la salud pueda prosperar. La protección de la salud ha de ser una preocupación de los otros sectores de la sociedad además del sanitario, y se tiene que incidir sobre todo en el ámbito formativo, insistiendo sobre los múltiples

5 Siguiendo parcialmente los objetivos de la Llei d'Ordenació Sanitària de Catalunya [1992, pp. $16-17]$. 
motivos existentes porque se dan los soportes a las actividades de protección, promoción y mejoría de la salud.

5. Atención apropiada por medio de un sistema sanitario basado en la atención primaria de la salud. Para alcanzar plenamente esta línea fijada por la OMS, es absolutamente necesario potenciar el médico de cabecera, fomentar el nuevo papel de la enfermería y trabajar conjuntamente en equipo, entendiendo que la incorporación de la prevención, de la educación sanitaria y de la rehabilitación son elementos importantes de la atención primaria de salud.

\subsubsection{CARACTERÍSTICAS DEL PROYECTO DE LA LOSC}

El Proyecto de Ley tiene como base la consideración de la sanidad como un servicio público financiado por el presupuesto general del Estado.

La creación del SCS, que constituye el eje fundamental de la ordenación sanitaria, nace con el objetivo de avanzar en la distribución adecuada de los recursos sanitarios, en la optimización de los recursos económicos que se destinan y en la coordinación de todo el dispositivo sanitario de cobertura pública, propiciando una simplificación, racionalización, eficiencia y eficacia de la organización sanitaria.

En el marco de una concepción integral de la salud, pretende estimular la participación comunitaria, potenciar la cualidad asistencial, estimular la humanización de la atención y por el respeto y dignidad de la persona y la libertad individual.

Para hacer efectivo el derecho a la protección de la salud, previsto en el artículo 43 y concordatarios de la Constitución Española, de esa manera como ejercicio de las competencias atribuidas a la Generalitat de Catalunya por los artículos 9, apartados 11 y 19, y 17 del Estatuto de Autonomía, el sistema sanitario público catalán se ordena de acuerdo con los principios de descentralización y desconcentración de la gestión, concepción integral de la salud, participación comunitaria, racionalización, eficacia, simplificación y eficiencia de la organización sanitaria, equidad y superación de las desigualdades, promoción de la salud, sectorización de la atención sanitaria y control sanitario del medio ambiente.

Para cumplir los objetivos de esta ordenación se crea el SCS como ente público, de carácter institucional, configurado por todos los recursos 
sanitarios públicos, y de cobertura pública, al cuál corresponden las funciones siguientes ${ }^{6}$ :

- Ordenación, planificación, programación y evaluación e inspección sanitarias, sociosanitarias y de salud pública.

- Distribución de los recursos económicos destinados al financiamiento de los servicios y prestaciones que configuran el sistema sanitario público y de cobertura pública, y el establecimiento, gestión y actualización de acuerdos, convenios y conciertos en materias de sanidad.

- Gestión y administración de los centros y establecimientos sanitarios integrados en el SCS, y también la ejecución de las actuaciones de los servicios y prestaciones del sistema sanitario público de Catalunya.

Se pretende, de esa manera, superar los fallos históricos de la organización sanitaria en relación con la desvinculación entre las actuaciones en materia de ordenación y planificación y las de gestión de los servicios sanitarios, que se portaba a termino por órganos distintos. Por este motivo, estas actuaciones se asignan a un órgano único, que las desarrollará con una dirección única, con vistas a una adecuada coordinación, teniendo presente la interrelación de las materias que conforman sus funciones.

La nueva concepción del SCS consolida la posibilidad de desarrollar fórmulas de gestión empresarial ya utilizadas por la administración sanitaria catalana, como son la figura del gerente y la previsión de diversas formulas de gestión — directa, indirecta o compartida - que el SCS puede emplear para la gestión de los servicios y las prestaciones del sistema sanitario público.

Desde una visión organizativa, el SCS se estructura de forma profundamente desconcentrada a través de unas demarcaciones territoriales denominados Regiones Sanitarias — RS — , que se corresponden con las áreas de salud previstas en la LGS, las cuales contarán con una dotación de recursos sanitarios de atención primaria integral y de atención especializada y hospitalaria suficientes para atender las necesidades de la población comprendida dentro de su territorio.

Dentro de la RS existen unas subunidades territoriales integradas, conformadas por un conjunto de Áreas Básicas de Salud —ABS—, y cuentan con unas estructuras desconcentradas de dirección, gestión y participación denominados Sectores Sanitarios - SS-.

6 Siguiendo parcialmente las funciones del SCS descritas en la Llei d’Ordenació Sanitària de Catalunya [1992, p. 18]. 
Estas estructuras permiten la integración de la atención primaria de salud y de los servicios de especialistas médicos y la coordinación de las actividades de promoción de la salud, la prevención de la enfermedad y salud pública, y también los recursos hospitalarios y extrahospitalarios públicos y de cobertura pública situados en el ámbito territorial específico del Sector.

El Proyecto de Ley configura el ABS como la unidad territorial elemental donde se presta la primera línea asistencial, y en el ámbito de la cuál, desarrolla sus actividades el Equipo de Atención Primaria —EAP— en el marco de una estructura física y funcional denominada Centro de Atención Primaria - $\mathrm{CAP}$ -

Las ABS integradas en un mismo SS se coordinarán entre ellas con la finalidad de conseguir los objetivos funcionales y asistenciales adecuados y, de esa manera, también con los servicios jerarquizados y especializados del Sector y con los hospitales que este tenga asignados.

El Proyecto de Ley institucionaliza la XHUP y consolida un sistema sanitario mixto propio, basado en el aprovechamiento de todos los recursos sanitarios existentes, ya sean públicos o privados, con objetivo de conseguir una óptima ordenación hospitalaria que haga posible una adecuada homogeneización de las prestaciones y la correcta utilización de los recursos humanos y materiales, de acuerdo con la tendencia general de los países desarrollados.

El Proyecto de Ley destina un capítulo a los medios personales y otro a los medios materiales de régimen patrimonial. Aborda el régimen financiero, presupuestario y contable, el régimen de impugnación de los actos, la responsabilidad, representación y defensa en juicio. Delimita las competencias de las comarcas y municipios, y prevé la existencia del Pla de Salut de Catalunya - PSC - como un instrumento indicativo y marco de referencia para todas las actuaciones públicas en la materia, y que se elabora por medio de una mecánica descentralizada que, partiendo del ABS, llega a los órganos centrales del SCS.

En el Proyecto de la LOSC se plasma también el principio de participación comunitaria dentro de la totalidad de las estructuras del SCS.

Esta representación se refleja a través de las corporaciones locales de los órganos colegiados de dirección de las RSs y de los órganos de participación establecidos en todos sus diversos niveles, en los cuales también tienen espacio las entidades sociales que en el ámbito sanitario son representativas del tejido social catalán.

El Proyecto de Ley también prevé otros aspectos sanitarios que se incluyen dentro de las actividades del SCS, como son la salud mental y la salud bucodental, 
la atención sociosanitaria a las personas grandes y a los enfermos crónicos, la planificación familiar y la salud laboral.

FIGURA 5.4. Estructura global del sistema sanitario público catalán.

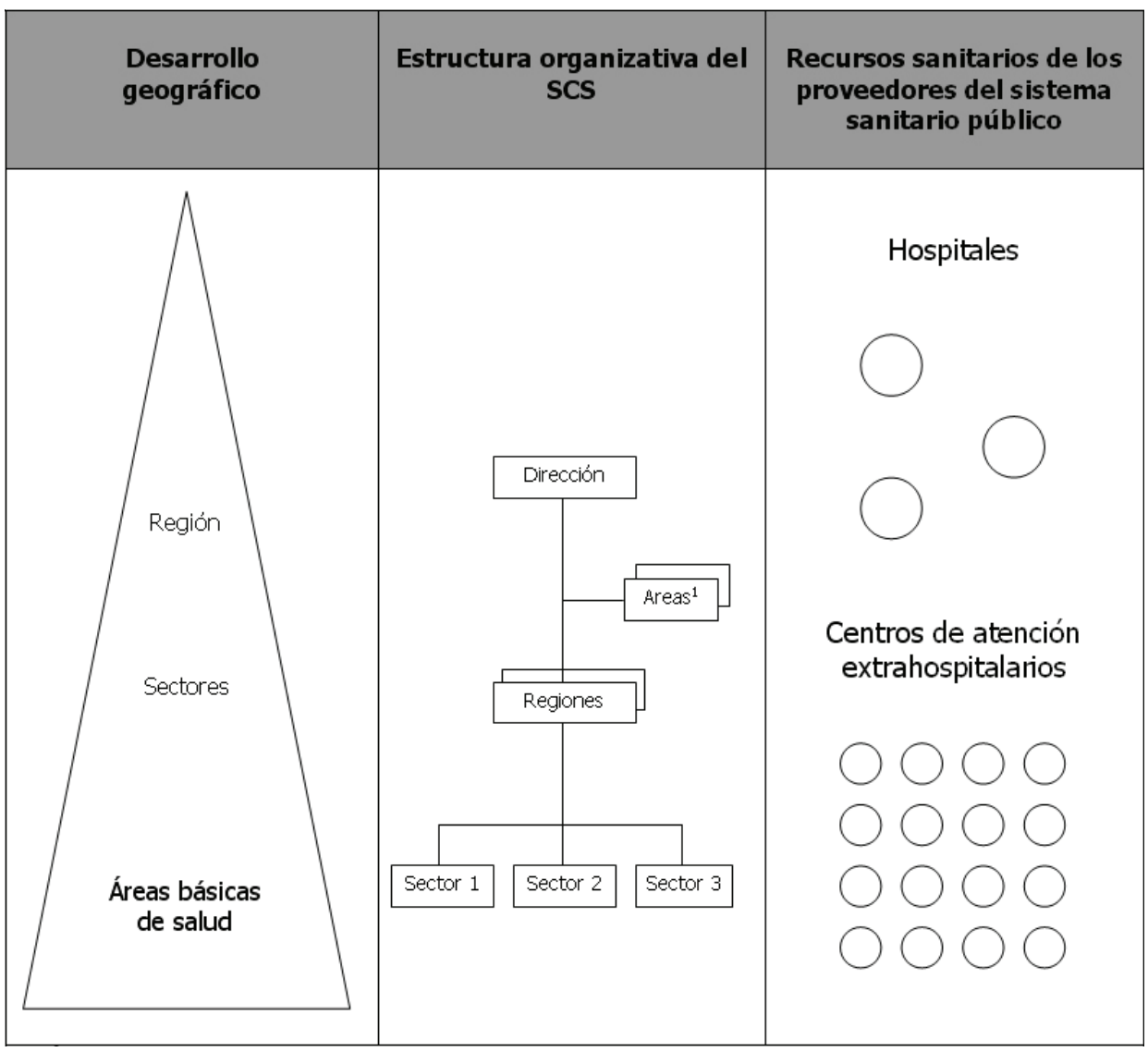

(C) McKinsey \& Company [1992, p. 4].

Un otro aspecto relevante del Proyecto es la introducción de un título específico dedicado al Institut d'Estudis de la Salut —IES- Se potencia este organismo como instrumento de soporte a los departamentos de la Generalitat y del SCS en materia de formación de los profesionales sanitarios y no sanitarios del campo de la salud y la investigación en ciencias de la salud. En el Anexo, se encuentra el Texto de la Llei 15/1990, de 9 de julio, de Ordenació Sanitària de Catalunya, aprobada por el Pleno del Parlament el día 14 de junio de 1990 [BOPC núm. 187 de 6 de julio de 1990] y publicada en el Diario Oficial de la Generalitat de Catalunya núm. 1.324 de 30 de julio de 1990. 


\subsubsection{MODIFICACIÓN DE LA LOSC}

La Ley 15/1990 del 9 de julio, ordena el sistema sanitario de Catalunya y establece la regulación general de todas las acciones relacionadas para hacer efectivo el derecho a la protección de la salud reconocido por los artículos 43 y concordatarios de la Constitución Española - CE— dentro del territorio de la Generalitat, en el marco de las competencias que le atribuye el artículo 9 apartados 11 y 19, y el artículo 17 del Estatuto de Autonomía -EA-.

Con esta configuración de ente público el legislador evitó de configurar el SCS como un organismo autónomo de carácter administrativo, con la voluntad de incluirle en la categoría de los entes públicos que, con carácter general, han de ajustar su actividad al derecho privado, categoría más adecuada a su condición de entidad configurada por todos los centros, servicios y establecimientos sanitarios públicos o privados de cobertura pública —artículo 5 de la Llei_ y a la diversidad de fórmulas de gestión directa, indirecta o compartida que el SCS puede utilizar a los efectos de la gestión y de la administración de los servicios y de las prestaciones del sistema sanitario público —artículo 7.2 del texto legal—.

Es por este motivo que, en aplicación del artículo 4 de la Llei 15/1990, del 9 de julio, el Decreto 26/1991, del 18 de febrero, primer, y posteriormente el Decreto 131/1994, del 30 de mayo, para concretar el régimen jurídico del SCS, han establecido en el artículo 1.1 que, por el que hace a las relaciones jurídicas externas, el SCS sujeta, con carácter general al derecho privado, sujeción que se mantiene plenamente en la nueva redacción del artículo 4 de la Llei 11/1995, en coherencia con el planteamiento anterior, que no tiene otras alteraciones que las derivadas de la obligada adecuación del régimen de contratación del SCS ante la legislación básica del Estado como consecuencia de la entrada en vigor de la Ley 13/1995, del 18 de mayo, de contratos de las administraciones públicas.

De esa manera, la experiencia conseguida en el proceso de consolidación del SCS a hecho necesario regular con más precisión el procedimiento a seguir para la constitución de organismos que de él dependan, la formación de consorcios y la creación, o la participación del SCS en éstos, o de cualesquiera otras entidades admitidas en derecho.

Finalmente, se completa la Llei con la inclusión de diversas normas orientadas al establecimiento de fórmulas para la gestión de los centros, los servicios y los establecimientos sanitarios y sociosanitarios que hagan posible un mayor grado de implicación de los profesionales en el proceso de desarrollo del sistema sanitario, que garanticen al SCS el acceso a la información poblacional necesaria para hacer efectiva, entre otras finalidades, la universalización de la atención sanitaria pública 
a todos los ciudadanos y, en último término, que permita al Institut Català de la Salut la realización de todos los actos y negocios jurídicos que sean necesarios para el desarrollo adecuado de las funciones que este organismo tiene atribuidas, de acuerdo con el régimen jurídico que le es aplicable.

En esta misma línea, esta ley impone al Gobierno de la Generalitat a establecer los sistemas de evaluación y control periódico de los diferentes centros proveedores de servicios sanitarios y sociosanitarios y verificar su grado de eficacia, eficiencia y calidad.

\subsection{EL MODELO SANITARIO PÚBLICO DE CATALUNYA}

El modelo sanitario que configura la Llei de ordenació sanitària de Catalunya _LOSC_- aprobada en 1990, es el resultado del conjunto de actuaciones del Departament de Sanitat i Seguretat Social de la Generalitat de Catalunya desde el traspaso de las transferencias de los servicios sanitarios de la Seguridad Social.

FIGURA 5.5. Modelo sanitario que configura la LOSC.

\begin{tabular}{|c|c|}
\hline Principios informadores & Características principales \\
\hline $\begin{array}{l}\text { - La sanidad es un servicio público, financiado } \\
\text { públicamente. } \\
\text { - Asistencia sanitaria universal, para todos. } \\
\text { - en la promoción de la salud y prevención de } \\
\text { la enfermedad. } \\
\text { - Equidad y superación de las desigualdades } \\
\text { territoriales y sociales en la prestación de los } \\
\text { servicios sanitarios. } \\
\text { - Racionalización, eficacia, simplificación y } \\
\text { eficiencia en la organización sanitaria. }\end{array}$ & $\begin{array}{l}\text { - Creación del Servicio Catalán de la Salud } \\
\text { como ente público responsable de la } \\
\text { prestación de los servicios sanitarios de } \\
\text { cobertura pública de la Generalitat de } \\
\text { Catalunya. } \\
\text { - Consolidación del sistema sanitario mixto } \\
\text { propio de Catalunya. } \\
\text { - Configuración de un mercado de } \\
\text { competencia planificada y regulada: } \\
\text { Separación de las funciones de financiación y } \\
\text { de provisión de servicios y proceso de } \\
\text { diversificación de proveedores. } \\
\text { - Descentralización de los servicios. } \\
\text { - Desconcentración de la organización del } \\
\text { Servicio Catalán de la Salud: división en } \\
\text { regiones y sectores sanitarios. } \\
\text { - Creación de un modelo de relaciones } \\
\text { laborales, en el seno de la corporación } \\
\text { - Servicio Catalán de la Salud. } \\
\text { - Piversidad de fórmulas de gestión. } \\
\text { Participación comunitaria en las estructuras } \\
\text { del Servicio Catalán de la Salud: consejos de } \\
\text { dirección y participación. }\end{array}$ \\
\hline
\end{tabular}

(C) Memòria d'activitat 1996 Servei Català de la Salut 1996 [1997, p. 12]. 
Catalunya fue la primera comunidad autónoma que recibió la transferencia del INSALUD, en 1981. En aquel momento era evidente la insuficiencia de recursos públicos y de inversiones realizadas por la Seguridad Social en Catalunya, y los desequilibrios territoriales en los servicios. Paralelamente, se había desarrollado una infraestructura sanitaria impulsada por las mutuas y entidades benéficas y asistenciales que respondían a las demandas de la sociedad y que permitieron complementar la red sanitaria propia de la Seguridad Social.

La gestión de los servicios sanitarios se inició con el despliegue del Mapa sanitario de Catalunya entre el 1981 y el 1983, una propuesta que recogía la voluntad de aprovechar todos los recursos existentes.

FIGURA 5.6. Organización del sistema sanitario en Catalunya.

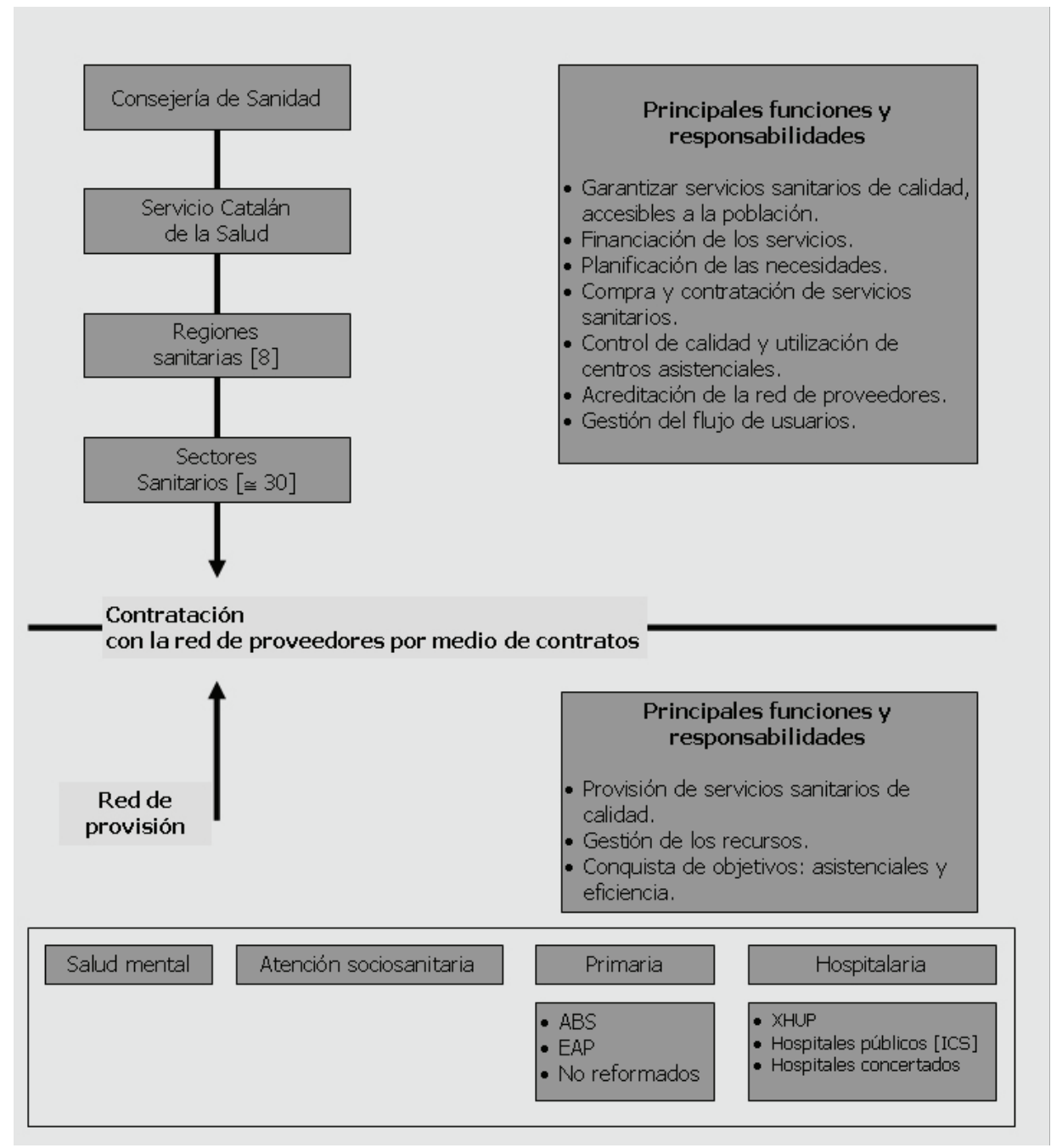

(C) Ruiz [1997, p. 5]. 
En 1983 se crea del Institut Català de la Salut como entidad gestora de las prestaciones y de los servicios sanitarios de la Seguridad Social. Durante los años siguientes se pone en marcha la reordenación hospitalaria y se crea la Red Hospitalaria de Utilización Pública —XHUP—, a la vez que se inicia la reforma de la atención primaria.

FIGURA 5.7. Esquema general de asistencia sanitaria en Catalunya.

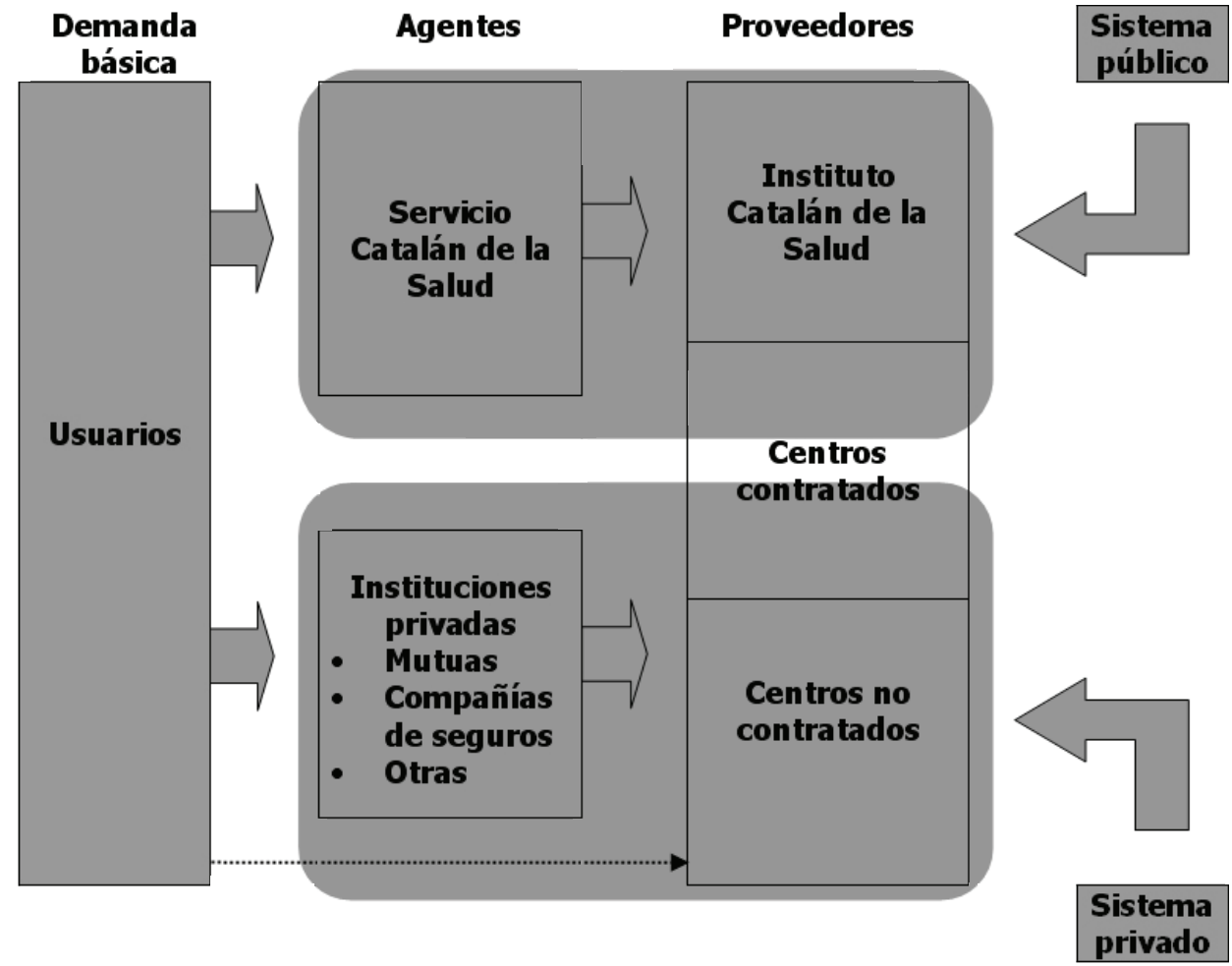

(C) McKinsey \& Company [1992, p. 6].

En 1986, la Ley General de Sanidad _-LGS - reconoce la universalización de la asistencia sanitaria a todos los ciudadanos e impulsa el establecimiento de servicios de salud en el ámbito de cada comunidad autónoma en el marco de un sistema nacional de salud.

En Catalunya, como paso previo al Servei Català de la Salut, en el año 1989 se crea la Dirección General de Recursos Económicos del Sistema Sanitario. Esta nueva estructura ya definía una distinción entre la compra de servicios de los centros sanitarios y la gestión directa de la producción. 
El modelo sanitario catalán se concretó en 1990 con la Llei de Ordenació Sanitària de Catalunya —LOSC_- que crea el Servei Català de la Salut —SCS_consolida el sistema sanitario mixto propio de Catalunya y extiende el modelo a todas las líneas de productos sanitarios y sociosanitarios. Este modelo ha ido desarrollándose progresivamente.

FIGURA 5.8. Situación de partida y visión futura del sistema asistencial público catalán.

\begin{tabular}{|c|c|c|}
\hline & Situación de partida & Visión futura \\
\hline Asistencia primaria & $\begin{array}{l}\text { - Coexistencia del sistema } \\
\text { tradicional con equipos de } \\
\text { asistencia primaria [EAP] } \\
\text { Titularidad mayoritariamente } \\
\text { de «Administración pública» } \\
\text { [ICS] }\end{array}$ & $\begin{array}{l}\text { Equipos de atención primaria } \\
\text { [EAP] } \\
\text { - Titularidad: coexistencia de } \\
\text { diferentes modelos }\end{array}$ \\
\hline $\begin{array}{l}\text { Asistencia } \\
\text { hospitalaria }\end{array}$ & $\begin{array}{l}\text { - Hospitales de «Administración } \\
\text { pública» [ICS] } \\
\text { - Hospitales concertados }\end{array}$ & $\begin{array}{l}\text { - Hospitales contratados [de } \\
\text { titularidad pública, semipública } \\
\text { o privada] }\end{array}$ \\
\hline $\begin{array}{l}\text { Relación entre } \\
\text { asistencia primaria } \\
\text { y hospitalaria }\end{array}$ & $\begin{array}{l}\text { - Independencia de los niveles } \\
\text { - Flujos controlados por el } \\
\text { proceso tradicional }\end{array}$ & $\begin{array}{l}\text { - Integración de la gestión de la } \\
\text { asistencia en el ámbito de } \\
\text { sector por encima de la gestión } \\
\text { de los centros } \\
\text { Integración operativa de los } \\
\text { especialistas en hospitales }\end{array}$ \\
\hline
\end{tabular}

(C) McKinsey \& Company [1992, p. 5].

Por un lado, se separaron las funciones de financiación de los servicios de las de producción, profundizando en el objetivo último de mantener y mejorar el estado de salud de la población, a través de los instrumentos esenciales de planificación, financiación, contratación y evaluación de los servicios sanitarios. Por otro lado, se desplegó la estructura corporativa de los servicios matrices y la estructura territorial de regiones y sectores sanitarios.

Y, finalmente, se potenció la diversidad de fórmulas de gestión como las empresas públicas, los consorcios o las cesiones de gestión.

En este sentido, la modificación de la LOSC hecha en 1995 introdujo algunas novedades que profundizan en el proceso de diversificación de proveedores en el ámbito de la atención primaria. 
FIGURA 5.9. Distribución de funciones de la sanidad pública en Catalunya.

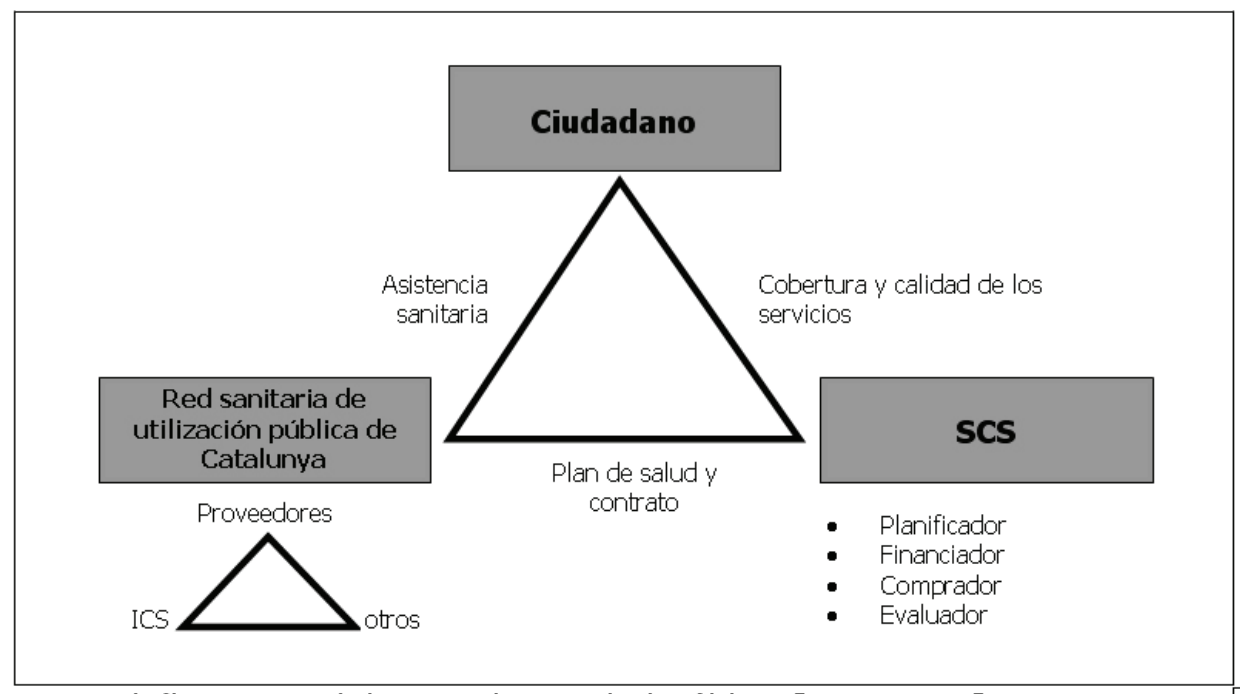

(C) Cataluña, un modelo para la sanidad pública [1997, p. 8].

\subsection{EL ENTORNO ECONÓMICO}

El nivel de gasto público que se debe destinar al denominado estado del bienestar es, año tras año, un de los aspectos más debatidos en el momento de plantear la distribución de los recursos públicos existentes. No es solamente el problema del su financiación o el de la mejoría de su gestión lo que ha generado este debate, el grado de preocupación colectiva que suscita, proviene de la constatación de que el estado del bienestar padece la suma o la unión de un conjunto de factores diversos.

Los informes sectoriales aconsejan generalmente reformas parciales que apuntan hacia su flexibilización, hacia una gestión más rigurosa de las necesidades sociales prioritarias o bien hacia la reestructuración de los presupuestos públicos. Este planteamiento, existente desde principios de los años ochenta con la segunda crisis del petróleo y potenciado extraordinariamente desde la recesión de principios de los años noventa, es mucho más claro en la actual Europa comunitaria, no solamente por la situación de incertidumbre que planea sobre las economías de los países miembros y, principalmente, por los retos que estos países habrán de afrontar en los próximos años para cumplir los acuerdos del Tratado de la Unión Europea - TUE - y garantizar su continuidad en la moneda única -Euro-. 
En el caso de la sanidad, todos los países desarrollados se encuentran en una situación de gasto creciente. Hasta ahora, los incrementos de los costes sanitarios fueran provocados por factores demográficos, pero también por la utilización de técnicas más sofisticadas y nuevas tecnologías, por la aparición de nuevas patologías y por el incremento del consumo de bienes de sanidad en todas las edades - la población espera una mejora continua en los niveles de servicios sanitarios-.

En términos económicos, la asistencia médica se considera como un bien de mérito — a medida que la gente dispone de más renta, tiende a consumir proporcionalmente más servicios sanitarios de forma que el gasto sanitario tiende a crecer más rápidamente que el producto interior bruto, PIB-.

Actualmente se tiene que agregar un nuevo factor que explica el crecimiento acelerado del gasto sanitario - el envejecimiento de la población-. Algunos estudios han concluido que el $60 \%$ de los gastos en sanidad que se producen a lo largo de la vida de una persona, se concentran en el año que precede a su muerte. Según una hipótesis media de evolución de la población, el envejecimiento haría incrementar el número de muertes hasta el año 2025 en un 17,5\%, proporción por la cuál se multiplicaría, el comentado, $60 \%$ de los costes de sanidad, únicamente por el efecto demográfico. Las hipótesis de la Comisión Europea para sus miembros apuntan que el número de personas mayores de 80 años aumentará 1,6 veces, los mayores de 85 años 2 veces, y los mayores de 90 años 2,8 veces, siempre en el período citado. Por tanto, es el número de personas mayores el que aumentará más rápidamente. Si se tiene en cuenta la correlación entre edad y gasto sanitario, la tendencia de la evolución demográfica hará aumentar todavía más los gastos en sanidad en los próximos años [Pla de Salut de Catalunya 1996-1998, p. 228].

La situación del gasto social en España adquiere ciertas variantes, principalmente por el esfuerzo que ha supuesto su crecimiento en las últimas décadas, ya que se ha hecho a un ritmo superior al del gasto corriente de las administraciones públicas, teniendo en cuenta que hoy, el gasto social en relación con el PIB continua siendo un de los más bajos de la Unión Europea. Sin ser una excepción, el gasto sanitario en España también ha experimentado un notable aumento con relación al PIB, pero es todavía significativamente inferior al de la mayoría de los países desarrollados. El mayor incremento de los gastos en sanidad se produce durante el período de desarrollo de los años sesenta y mitad de los setenta, cuando se partía de niveles muy bajos. Durante el período siguiente, hubo una lentitud inicial — durante la crisis del petróleo-, hasta que la Ley 
general de sanidad - LGS-, en el año 1986, da un nuevo impulso en el gasto sanitario, en una fase de recuperación económica y con un ritmo de crecimiento superior al del PIB. La última década, como consecuencia del cambio en la estructura de financiación que provocó la LGS, el gasto sanitario público pasó a depender mayoritariamente de las aportaciones del Estado.

TABLA 5.1. Producto interior bruto y gasto sanitario [1984—1994].

\begin{tabular}{|c|c|c|c|c|c|c|}
\hline \multicolumn{3}{|c|}{ Entorno económico } & \multicolumn{4}{|c|}{ Gasto sanitario } \\
\hline \multirow[t]{2}{*}{ Año } & \multirow{2}{*}{\begin{tabular}{|c|} 
PIB \\
Millardos de \\
Ptas. 1994
\end{tabular}} & \multirow{2}{*}{\begin{tabular}{|c|}
$\begin{array}{c}\text { PIB } \\
\text { per cápita }\end{array}$ \\
Ptas. 1994
\end{tabular}} & \multirow{2}{*}{$\begin{array}{c}\begin{array}{c}\text { Gasto sanitario } \\
\text { tota I }\end{array} \\
\text { Millardos de } \\
\text { Ptas. } 1994 \\
\end{array}$} & \multirow{2}{*}{$\begin{array}{c}\begin{array}{c}\text { Gasto sanitario } \\
\text { total } \\
\text { per cápita }\end{array} \\
\text { Ptas. } 1994\end{array}$} & \multicolumn{2}{|c|}{$\begin{array}{c}\text { Gasto sanitario } \\
\text { total como } \\
\text { porcentaje del } \\
\text { PIB }\end{array}$} \\
\hline & & & & & España & UE \\
\hline 1984 & 13.534 .635 & 353.127 & 781.444 & 20.388 & 6,0 & 7,5 \\
\hline 1985 & 16.307 .899 & 423.868 & 925.202 & 24.047 & 5,8 & 7,5 \\
\hline 1986 & 20.271 .389 & 525.111 & 1.139 .550 & 29.519 & 5,7 & 7,6 \\
\hline 1987 & 24.134 .170 & 623.364 & 1.375 .560 & 35.530 & 5,6 & 7,6 \\
\hline 1988 & 28.497 .148 & 734.292 & 1.805 .952 & 46.534 & 5,7 & 7,7 \\
\hline 1989 & 34.177 .538 & 878.871 & 2.229 .508 & 57.332 & 6,3 & 7,6 \\
\hline 1990 & 40.715 .118 & 1.045 .076 & 2.817 .793 & 72.327 & 6,5 & 7,7 \\
\hline 1991 & 47.961 .478 & 1.222 .075 & 3.254 .811 & 83.403 & 6,9 & 8,0 \\
\hline 1992 & 54.330 .954 & 1.389 .894 & 3.777 .527 & 96.637 & 6,8 & 8,1 \\
\hline 1993 & 58.580 .982 & 1.496 .207 & 4.270 .123 & 109.062 & 7,0 & 8,2 \\
\hline 1994 & 64.838 .160 & 1.653 .613 & 4.960 .000 & 126.498 & 7,3 & 8,3 \\
\hline
\end{tabular}

(C) NERA [1997, p. 179].

Una de las razones por las cuáles en España —al igual que en otros paísesse ha planteado la viabilidad del estado del bienestar, fue la exigencia del control del déficit público, que impone de manera general el TUE y que ha llegado a ser uno de los indicadores de convergencia nominal para tener acceso a la Unión Monetaria.

En el artículo 104C del TUE, se afirma que, de manera general, los estados miembros tendrán que evitar pérdidas públicas excesivas y, y sin hacer justificación de esta exigencia, se considera del 3\% la proporción entre el déficit público previsto o real y el PIB a precios de mercado [Pla de Salut de Catalunya 19961998, p. 229].

Por este motivo, los presupuestos públicos en los últimos años, y particularmente en el 1997, año que servio de base para evaluar el cumplimiento 
de los objetivos de convergencia establecidos en el TUE, han de combinar, la austeridad de los sus planteamientos con tasas de crecimiento del PIB más elevadas que las anteriores. En España, el crecimiento sostenido de la economía está condicionado, en buena medida, por el descenso de los tipos de interés -hoy con niveles históricos de los tipos de interés aplicados por el Banco Central Europeo, por debajo del 3\%-.

Los elementos básicos del proyecto de Presupuesto del Estado para el año 1998 recogían un déficit próximo a los dos billones de pesetas, cifra que representaba un 2,5\% del PIB —el déficit restante, hasta el 3\% del PIB, correspondía a la Seguridad Social y a las administraciones territoriales-. Fue previsto que el gasto aumentase por bajo del $2 \%$, claramente inferior al incremento del PIB nominal — 6\% - En lo referente a las expectativas de financiación de la sanidad, se puede comentar, en primer lugar, los acuerdos a que llegaron todos los partidos políticos el febrero del 1995 sobre la reforma de la Seguridad Social en el denominado Pacto de Toledo. Entre las recomendaciones que hace el citado informe, figura la separación y clarificación de las fuentes de financiación de la Seguridad Social, en el sentido que las prestaciones contributivas continúan financiadas por las cotizaciones sociales y las prestaciones no contributivas y universales, entre las cuales está la sanidad, continúan financiadas vía impuestos. Esta recomendación ya se ha hecho patente en los presupuestos del Instituto Nacional de la Salud _-INSALUD — desde el año 1995, en que la aportación del Estado incrementa su participación, compensando así una disminución de los ingresos por cotizaciones sociales. El escenario presupuestario de los servicios sanitarios de la Seguridad Social se fijó por el acuerdo firmado en diciembre de 1994 entre el Ministerio de Economía y Hacienda y todas las comunidades autónomas con competencias en materia de sanidad, por el cuál se modificaba el sistema de financiación de la sanidad para el período 1994-1997. Este acuerdo tenia por objetivo acabar con el problema de la insuficiencia financiera que históricamente sufre el sistema sanitario público y, al mismo tiempo, fijar un escenario estable de crecimiento de los recursos para este período.

El modelo tomaba como referencia, para fijar el punto de partida, el gasto efectivo del INSALUD en el año 1993 y establecía, para los próximos años, que el presupuesto destinado a la sanidad creciese al mismo ritmo que la economía, es decir, igual que la tasa de crecimiento del PIB nominal. Sin embargo, el modelo introducía un factor restrictivo ya que incorporaba una deducción de 90.000 millones de pesetas sobre la base en concepto de medidas de ajuste y racionalización del gasto sanitario. Se debe tener presente que las bases que establecía el acuerdo 
firmado ya suponían una importante restricción económica para la sanidad, ya que el crecimiento del gasto sanitario en los últimos años se había situado una media de tres puntos por sobre del crecimiento del PIB nominal. Si a este punto sumamos que la base de partida del modelo que se acordó era inferior al gasto real del Sistema Nacional de Salud, resulta que el escenario económico presupuestario por el período 1994-1997 se encontraba todavía lejos de conseguir el principio de suficiencia financiera.

También se debe considerar que en los últimos años se están produciendo una serie de hechos como la universalización de la cobertura, la aparición de nuevas patologías, el envejecimiento de la población y la introducción progresiva de nuevas tecnologías médicas que están impulsando fuertemente el crecimiento del gasto sanitario y que dificultan de forma importante el cumplimiento de escenarios restrictivos.

En julio de 1995, el Ministerio de Economía revisó el escenario presupuestario, corrigiendo a la baja la base de partida del modelo y aumentando la deducción por medidas de ajuste y racionalización del gasto, haciendo que la revisión del escenario que preveía el acuerdo en el momento que se conociesen los datos definitivos de la tasa de crecimiento del PIB nominal, tuvo como resultado una importante reducción de los recursos a transferir a las comunidades autónomas con respecto al escenario acordado el diciembre de 1994.

El escenario del proyecto de presupuesto sanitario para el año 1997 se realizó respetando la previsión de la tasa de crecimiento del PIB nominal del $6 \%$ y bajo la hipótesis que los ahorros que se produjeran por la aplicación de las medidas de contención del gasto que preveía aplicar el Estado, como la congelación de las retribuciones de los empleados públicos del sistema sanitario o los acuerdos sobre la prestación farmacéutica, revirtiesen en la financiación de los servicios sanitarios.

Así, el presupuesto del INSALUD para el año 1997 fue de 3.561.864 millones de pesetas, de los cuales 2.188 .063 millones — $61,43 \%$ - se transfirieron a las comunidades autónomas que han asumido las competencias en materia de sanidad - Catalunya, Andalucía, País Vasco, Comunitat Valenciana, Galicia, Navarra y Canarias—. La financiación del presupuesto del INSALUD se realiza básicamente por medio de la aportación finalista del Estado —91,88\%—, habiendo perdido participación los ingresos por cotizaciones sociales que han pasado del 14,91\% en el año 1996 al 5,61\% en el año 1997, de acuerdo con las recomendaciones que sobre la financiación de la sanidad incluye el Pacto de Toledo. 


\subsubsection{ASIGNACIÓN DE RECURSOS $1993-1996$}

La planificación de los recursos económicos se ha orientado tomando como base objetivos de salud, dando prioridad las actuaciones más eficaces y eficientes para conseguir resultados sobre la salud de la población.

En la tabla 5.2 se puede observar la evolución del coste de la prestación de servicios sanitarios entre los años 1993 y 1996, expresado como el porcentaje de variación interanual. Independiente del contexto económico fuertemente restrictivo de este período, se han incrementado los recursos destinados en todas las líneas de servicios.

TABLA 5.2. Variación interanual del coste de la prestación de servicios sanitarios. Catalunya 1993-1996.

\begin{tabular}{|c|c|c|c|}
\hline & $1994-1993$ & 1995-1994 & $1996-1995^{4}$ \\
\hline Total prestación de servicios sanitarios & 3,25 & 6,59 & 5,21 \\
\hline Atención primaria $^{1}$ & 5,56 & 7,96 & 5,35 \\
\hline Atención especializada ${ }^{2}$ & 1,77 & 5,54 & 4,45 \\
\hline Salud mental ${ }^{3}$ & 7,14 & 9,36 & 10,68 \\
\hline Vida a los años & 10,84 & 13,64 & 13,75 \\
\hline Prestación farmacéutica & 5,19 & 11,76 & 13,56 \\
\hline \multicolumn{4}{|c|}{$\begin{array}{l}\text { 1. En atención primaria se incluyen los recursos destinados a: } \\
\text { - Servicios de diagnóstico y tratamiento extrahospitalario. } \\
\text { - Equipos de atención primaria. } \\
\text { - Red no reformada. } \\
\text { - Especialistas de contingente. } \\
\text { - Desplazamientos y prestaciones ortopédicas. } \\
\text { 2. En atención especializada se incluyen los recursos destinados a: } \\
\text { - Atención especializada. } \\
\text { - Programa de atención a la insuficiencia renal. } \\
\text { - Medicación hospitalaria de dispensa ambulatoria. } \\
\text { 3. En salud mental se incluyen todos los recursos destinados al programa, ya sean por medio de } \\
\text { transferencias del SCS como por la contratación de servicios sanitarios. } \\
\text { 4. El coste } 1996 \text { es una estimación. }\end{array}$} \\
\hline
\end{tabular}

(C) Pla de salut de Catalunya 1996-1998 [1997, p. 232].

\subsubsection{EL PRESUPUESTO DESTINADO A SERVICIOS SANITARIOS PARA EL AÑO 1997}

El anteproyecto de presupuesto para la prestación de los servicios sanitarios de provisión pública de la Generalitat de Catalunya para el año 1997 — tabla 5.3 - alcanza los 605.807 millones de pesetas, representa, aproximadamente, un tercio del presupuesto de la Generalitat de Catalunya y supone un incremento del 6\% respecto del año 1996. 
La tabla 5.3 muestra la evolución del presupuesto y del porcentaje de variación interanual para la prestación de los servicios sanitarios de provisión pública de la Generalitat de Catalunya desde el año 1991 hasta el año 1997, tomando como referencia el año 1981.

El entorno económico para el período de vigencia del Pla de salut 19961998 ha venido marcado por el ajuste de los gastos públicos que obligó las administraciones a tomar medidas para garantizar a la población unos servicios sanitarios de calidad que puedan ser financiados en el futuro.

TABLA 5.3. Anteproyecto de presupuesto 1997 de la Generalitat de Catalunya destinado a las prestaciones sanitarias.

\begin{tabular}{|c|c|c|}
\hline Atención primaria ${ }^{1}$ & 260.251 & $44,38 \%$ \\
\hline Atención especializada² & 298.228 & $50,86 \%$ \\
\hline Salud mental & 12.900 & $2,20 \%$ \\
\hline Vida a los años & 15.000 & $2,56 \%$ \\
\hline Total & $586.379^{3}$ & $100 \%$ \\
\hline \multicolumn{3}{|c|}{$\begin{array}{l}\text { En millones de pesetas. } \\
\text { 1. Incluye las prestaciones de transporte, las prótesis ortopédicas y las prestaciones farmacéuticas. } \\
\text { 2. Incluye la atención a la insuficiencia renal. } \\
\text { 3. Excluye los gastos de administración y las operaciones de capital. }\end{array}$} \\
\hline
\end{tabular}

(C) Pla de salut de Catalunya 1996_-1998 [1997, p. 234]. 
TABLA 5.4. Evolución del presupuesto y del porcentaje de variación interanual para la prestación de los servicios sanitarios de provisión pública de la Generalitat de Catalunya, 1981-1997.

\begin{tabular}{|c|c|c|c|c|c|}
\hline \multicolumn{6}{|c|}{ Variación interanual $\multimap \%-$} \\
\hline Año & $\begin{array}{c}\text { Pesetas } \\
\text { corrientes }\end{array}$ & $\begin{array}{c}\text { Pesetas } \\
\text { constantes }\end{array}$ & Período & $\begin{array}{c}\text { Pesetas } \\
\text { corrientes }\end{array}$ & $\begin{array}{c}\text { Pesetas } \\
\text { constantes }\end{array}$ \\
\hline $1981^{1}$ & 92.940 & 92.940 & - & - & - \\
\hline 1982 & 107.080 & 93.930 & $1981-1982$ & 15,21 & 1,07 \\
\hline 1983 & 135.498 & 105.934 & $1982-1983$ & 26,54 & 12,78 \\
\hline 1984 & 148.136 & 106.252 & $1983-1984$ & 9,33 & 0,30 \\
\hline 1985 & 163.073 & 108.101 & $1984-1985$ & 10,08 & 1,74 \\
\hline 1986 & 176.047 & 107.758 & $1985-1986$ & 7,96 & 0,32 \\
\hline 1987 & 197.641 & 115.655 & $1986-1987$ & 12,27 & 7,33 \\
\hline 1988 & 231.239 & 127.898 & $1987-1988$ & 17,00 & 10,59 \\
\hline 1989 & 271.439 & 140.442 & $1988-1989$ & 17,38 & 9,81 \\
\hline 1990 & 326.888 & 158.809 & $1989-1990$ & 20,43 & 13,08 \\
\hline 1991 & 379.946 & 174.962 & $1990-1991$ & 16,23 & 10,17 \\
\hline 1992 & 437.377 & 191.272 & $1991-1992$ & 15,12 & 9,32 \\
\hline 1993 & 491.102 & 204.734 & $1992-1993$ & 12,28 & 7,04 \\
\hline 1994 & 526.676 & 210.513 & $1993-1994$ & 7,24 & 2,82 \\
\hline 1995 & 552.237 & 211.629 & $1994-1995$ & 4,85 & 0,53 \\
\hline $1996^{2}$ & 571.566 & 211.834 & $1995-1996$ & 3,50 & 0,10 \\
\hline $1997^{2}$ & 605.807 & 218.835 & $1996-1997$ & 5,99 & 3,30 \\
\hline \multicolumn{6}{|c|}{$\begin{array}{l}\text { Año base } 1981 \text {. } \\
\text { En millones de pesetas. } \\
\text { 1. Presupuesto de transferencia según el Real Decreto } 1517 / 1981 \text {. } \\
\text { 2. Los indices de precios al consumo para los años } 1996-3,4 \%-\text { y } 1997-2,6 \% \text { - son datos del Ministerio } \\
\text { de Economía y Hacienda. }\end{array}$} \\
\hline
\end{tabular}

(C) Pla de salut de Catalunya 1996-1998 [1997, p. 235].

El año 1994 se firmó un acuerdo entre el Estado y las comunidades autónomas para garantizar que, a pesar de la situación de restricción en los presupuestos públicos, los recursos destinados a la sanidad crecerían al mismo nivel que el PIB. Este ritmo de crecimiento es sensiblemente inferior al de la tendencia del gasto, pero es superior al ritmo de crecimiento de los presupuestos globales de las administraciones públicas en los últimos años. El presupuesto del año 1997 y las negociaciones del año 1998 han conseguido respetar el crecimiento del PIB como criterio de evolución del presupuesto sanitario, criterio que también se habrá de seguir en el ejercicio del año 1999, en el cuál la previsión de crecimiento del PIB nominal según la Comisión 
Europea — crecimiento real del PIB más deflacionista— se prevé que estará alrededor del 6,2\%.

\subsubsection{Modelo de financiación de la sanidad para el período 1998 - 2001}

El 27 de noviembre de 1997 se aprobó el nuevo modelo de financiación de la sanidad. De esta manera quedó configurado el escenario de financiación del Sistema Nacional de Salud para al período 1998-2001, lo que supone una mejoría respecto al escenario existente hasta el 1997.

El sistema de financiación que se aplicó hasta el 1993 se caracterizó por su insuficiencia financiera y porque no era un sistema homogéneo, visto que existía un criterio de distribución diferente para cada comunidad autónoma. La reforma del modelo de financiación para el período 1994-1997 estableció que el presupuesto destinado a la sanidad crecería al mismo ritmo que el PIB nominal e introducía una deducción económica en concepto de medidas de ajuste, lo que suponía una importante restricción económica para la sanidad, teniendo en cuenta los factores que impulsan el crecimiento del gasto sanitario, como la universalización de la cobertura, la aparición de nuevas patologías, el envejecimiento de la población y la introducción progresiva de nuevas tecnologías médicas.

El nuevo modelo de financiación de la sanidad para el cuadrienio 1998 2001, aprobado por el Consejo de Política Fiscal y Financiera, supone un incremento de presupuesto para el conjunto del Sistema Nacional de Salud de 143.000 millones de pesetas — 3,88\% — respecto a la prórroga del modelo. El nuevo acuerdo supone el establecimiento de dos fondos diferenciados con los recursos a distribuir. En primer lugar, un fondo general destinado a la cobertura de las prestaciones sanitarias generales, dotado con 3,77 billones de pesetas, eso es el $98,2 \%$ del total de recursos, que se distribuyen de acuerdo con la población protegida, calculada con el padrón de habitantes de 1996 y deduciendo los colectivos protegidos por otros regímenes. Dentro de este fondo general existe 40.000 millones de pesetas condicionados al establecimiento de programas y medidas de control del gasto social en incapacidad temporal.

En segundo lugar, se establece un fondo de atención específica destinado a la financiación de los centros de docencia y a la compensación por la atención hospitalaria a los enfermos desplazados de otras comunidades autónomas — 48.000 millones- y un fondo de 20.000 millones para garantizar una financiación mínima a las comunidades autónomas que experimenten una disminución significativa del 
porcentaje de población relativa, como es el caso de Catalunya. Por otro lado, el acuerdo prevé como financiación adicional una reducción del gasto sanitario de 65.000 millones de pesetas como consecuencia del establecimiento de medidas de ahorro en farmacia y que a partir del año 2000 se producirá un incremento adicional del presupuesto de 25.000 millones de pesetas, condicionado a los resultados conseguidos con los objetivos de mejora de las listas de espera en intervenciones quirúrgicas y de control de calidad de los centros sanitarios. Con relación al criterio de evolución de estos recursos para el cuadrienio 1998-2001, el acuerdo considera como criterio la tasa de crecimiento del PIB nominal, como en el anterior modelo. Como resultado de este acuerdo, Catalunya recibirá unos ingresos adicionales de 33.759 millones de pesetas, un 5,71\% por sobre los recursos de la prórroga del modelo, a los cuales se tienen que sumar 10.237 millones de pesetas como ahorro en gasto farmacéutico en 1998. Si tenemos en cuenta, a más, que no se han deducir del presupuesto base los importes correspondientes a medidas de ahorro adoptadas en 1997 - congelación salarial y acuerdos con la industria farmacéutica一, se suman 11.025 millones de pesetas más, cosa que daría un total de 55.021 millones de pesetas.

El acuerdo, en cambio, no ha incorporado el saneamiento de la situación de deficiencias de los años anteriores y, por tanto, obliga a absorber con este crecimiento de recursos las insuficiencias históricas.

TABLA 5.5. Incremento de recursos del nuevo modelo de financiación para las comunidades autónomas.

\begin{tabular}{|l|r|r|}
\hline \multicolumn{2}{|c|}{ Distribución de recursos \% } & Incremento \% \\
\hline Catalunya & 16,27 & 5,71 \\
\hline Galicia & 6,93 & 2,36 \\
\hline Andalucía & 18,07 & 5,93 \\
\hline Valencia & 10,13 & 4,91 \\
\hline Canarias & 4,02 & 7,39 \\
\hline País Vasco & 5,44 & 2,02 \\
\hline Navarra & 1,35 & 2,02 \\
\hline Total de servicios transferidos & 62,21 & 4,96 \\
\hline INSALUD gestión directa & 37,79 & 2,16 \\
\hline Total del Sistema Nacional de Salud & $\mathbf{1 0 0 , 0 0}$ & $\mathbf{3 , 8 8}$ \\
\hline
\end{tabular}

(C) Memòria d'activitat 1997 del Servei Català de la Salut [1998, p.13]. 


\subsection{FUNDAMENTOS DE LA PLANIFICACIÓN DE LA SALUD}

El Pla de salut de Catalunya se basa en una orientación positiva del concepto de salud agregado a la mejora del bienestar de los ciudadanos. A partir del conocimiento del estado de salud de la población y de los sus determinantes, el Plan formula propuestas dirigidas a promover una mejor calidad de vida, ofrecer servicios más eficaces y eficientes y dar atención personalizada a los usuarios.

La naturaleza multicasual del binomio salud-enfermedad y la influencia que la biología, la educación, el nivel económico, los estilos de vida y el medio ambiente tienen en la salud y en la calidad de vida de los individuos, da un marcado carácter intersectorial en la planificación sanitaria. Planificar en el ámbito de la salud es especialmente complejo porque intervienen multitud de factores, los cuales dependen prácticamente de todas las esferas del entorno. Por otro lado, toda planificación se realiza en un contexto organizacional y sociopolítico al cuál están íntimamente ligadas todas las etapas de su proceso. El contexto sanitario actual se caracteriza por la aparición de nuevos retos de gran magnitud —envejecimiento progresivo de la población, cambios en el prevalecimiento de ciertas patologías, insuficiencia de recursos económicos, constante introducción de tecnologías y procedimientos complejos, etc.-. Por eso, los sistemas sanitarios de los países desarrollados han de afrontar estos cambios con una reorientación cada vez más eficaz y eficiente de sus intervenciones [Pla de salut de Catalunya 1996-1998, 1997, p. 19].

En Catalunya, la LOSC, aprobada por el Parlamento, establece las bases del modelo de sistema sanitario y hacia donde se ha de avanzar, por medio de la planificación sanitaria y la ordenación de los recursos, para garantizar la salud de la población. El modelo sanitario catalán se basa en la creación y el desarrollo del Servei Català de la Salut como máximo ente responsable de la atención sanitaria. Así mismo, se define un instrumento principal de planificación, el Pla de salut de Catalunya, que, a partir de la situación de salud y enfermedad de la población y los factores que la condicionan, explícita cuales han de ser las actividades de salud prioritarias, las medidas que se han de tomar en otros sectores que afectan la salud y los ámbitos preferentes de actuación. El objeto último de la planificación es ejecutar las intervenciones dirigidas a la mejoría de la salud y la calidad de vida de la población. 
FIGURA 5.10. Planificación y desarrollo del Plan de Salud.

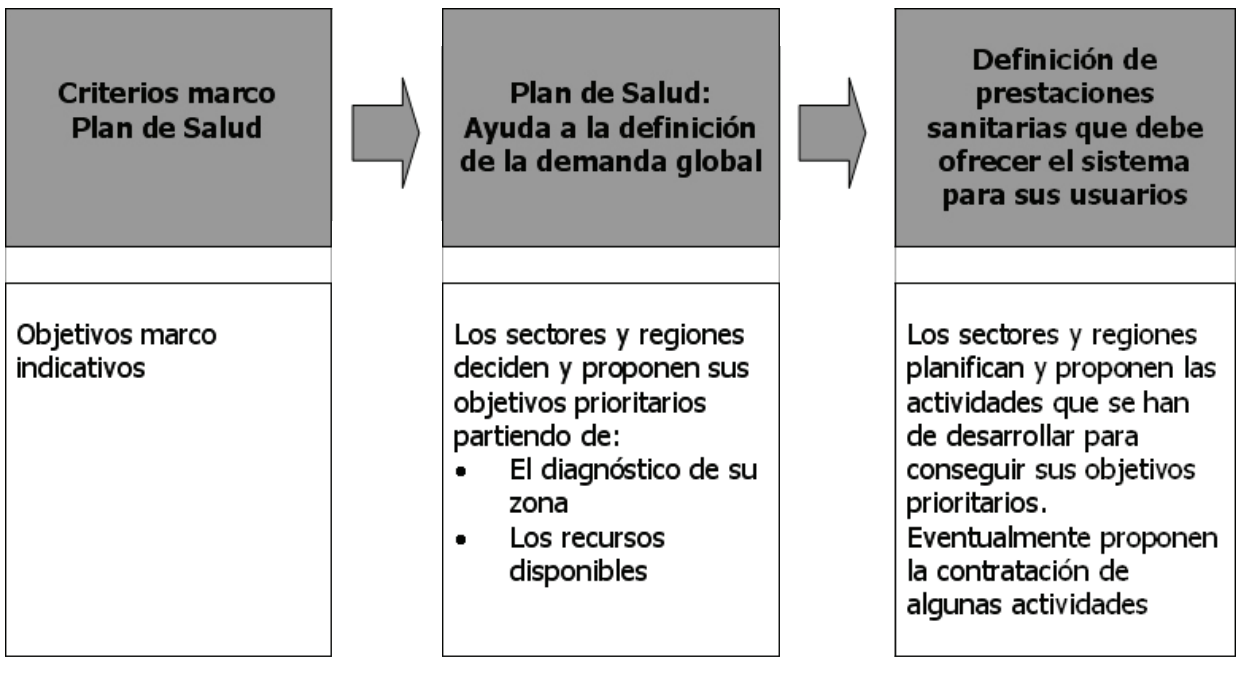

(C) McKinsey \& Company [1992, p. 8].

En Catalunya, la planificación sanitaria se basa en la estrategia definida por la Oficina Regional Europea de la Organización Mundial de la Salud, conocida como «Salud para todos en el año 2000», y las intervenciones que se proponen tienen en cuenta los acuerdos y las recomendaciones de las sociedades científicas y de los expertos tanto en el ámbito nacional como internacional, evolucionando desde una planificación de recursos hacia una planificación en salud, donde se ha pasado de centrar los objetivos primordialmente en la organización y en la productividad de los servicios para hacerlo en la salud de los ciudadanos y extender la responsabilidad sobre la salud a otros ámbitos no estrictamente sanitarios.

\subsubsection{EJES Y LÍNEAS ESTRATÉGICAS DE LA PLANIFICACIÓN DE LA SALUD EN CATALUNYA}

Las propuestas del Plan se orientan en la conquista de los objetivos generales de salud y de disminución de riesgo fijados para Catalunya para el año 2000, que recoge el «Document marc» para la elaboración del Pla de salut de Catalunya, así como de los objetivos relacionados con otros ámbitos de intervención priorizados.

El Pla de salut incluye actuaciones desde el punto de vista organizativo y de reequilibrio territorial de forma que el sistema sanitario catalán pueda 
adecuarse a las necesidades reales de la población y disminuir las situaciones de desigualdad.

Así mismo, el Pla de salut es un instrumento de planificación dinámico y con capacidad de adaptación a las necesidades de la población en términos de salud, que propone intervenciones que se ajustan a los cambios del entorno sanitario y socioeconómico, los cuales se articulan alrededor de los siguientes ejes ${ }^{6}$ :

- Promoción de la salud y prevención de la enfermedad.

- Equidad, eficiencia y calidad de los servicios.

- Satisfacción de los usuarios.

\subsubsection{TEMPORALIDAD DE LA PLANIFICACIÓN}

Se considera que la planificación de la salud es un proceso continuo de previsión de los recursos y de los servicios necesarios para conseguir los objetivos determinados según un orden de prioridades establecida. El diseño, la aplicación y la evaluación de las intervenciones dirigidas a la mejora del estado de salud requieren el planteamiento de unos períodos temporales suficientes para su ejecución. Se debe considerar que toda planificación estratégica ha de ser realizada en un contexto estrechamente relacionado con el entorno organizativo, económico y político que envuelve el sistema de salud.

La LOSC establece que el Pla de salut de Catalunya tendrá un período de vigencia trienal. Los resultados de la evaluación del período de vigencia y aplicación del Plan, las condiciones organizativas del sistema sanitario, las características de los procesos de planificación estratégica y los períodos temporales necesarios para detectar cambios significativos en los indicadores de salud y de utilización de servicios, son elementos de gran influencia en el establecimiento de la temporalidad de la planificación. También, es importante considerar que los objetivos generales de salud y de disminución de riesgo que constituye el fundamento de las propuestas del Pla de salut, tienen como horizonte el año 2000, en el cuál serán evaluados.

En este sentido, para algunas actuaciones priorizadas en el Pla de salut vigente, se han fijado objetivos e intervenciones que tienen su propia temporalidad —algunas con una fecha de finalización que sobrepasa el trienio-, que amplía,

6 Las propuestas se orientan hacia el logro de los objetivos generales de salud y de disminución del riesgo [Pla de salut de Catalunya 1996-1998, 1997, p. 20]. 
en algunos casos, el período de operativización hasta el año 2000. Al final del período de vigencia del Pla de salut se prevé la evaluación, reorientación y ampliación de sus contenidos.

La acción es lo que da sentido a la planificación y, por eso, el objetivo esencial del Pla de salut de Catalunya 1996-1998 es conseguir que las actuaciones prioritarias sean las pertinentes, las más efectivas y, al mismo tiempo, las más factibles para mejorar la salud y la calidad de vida de los ciudadanos. El nivel de efectividad de las intervenciones direccionadas a la mejora de la salud de la población es diverso, el que, juntamente con la limitada disponibilidad de recursos, obliga a priorizar tanto las intervenciones que se han de efectivar como los instrumentos para su aplicación. La planificación sanitaria en Catalunya tiene en cuenta la descentralización de los trabajos de planificación y de evaluación en las estructuras territoriales del Servei Català de la Salut, las regiones y los sectores sanitarios, el que hace posible mejorar el conocimiento de los problemas, diseñar las intervenciones más idóneas y favorecer la participación de los profesionales y de la población.

En Catalunya, la importancia de las regiones sanitarias en la planificación queda reflectada en la propia LOSC, que en el su artículo 22 párrafo 1 epígrafe $\mathrm{C}$ habla, textualmente, que son funciones propias de las regiones sanitarias «la gestión y la ejecución de las actuaciones y los programas institucionales en materia de promoción y protección de la salud, prevención de la enfermedad, asistencia sanitaria y sociosanitaria, y rehabilitación, de acuerdo con el Pla de salut de la región».

En este sentido, las necesidades de salud específicas solamente se pueden conocer desde el mismo territorio donde se plantean, porque, las desigualdades entre grupos que existe dentro de un país son difícilmente identificables si se tiene, únicamente una visión global.

También, para que las intervenciones sean factibles, es necesario el contraste con los recursos de que dispone la zona concreta de aplicación. Por este motivo el Pla de salut de Catalunya se elabora a partir de los planteamientos de los planes de salud de las regiones sanitarias.

El Pla de salut, como herramienta de planificación útil para la acción, se concreta de manera específica en la asignación de los recursos económicos y organizativos, la gestión de los servicios sanitarios, la evaluación de la calidad de la atención, el impacto de las acciones intersectoriales, la participación y satisfacción de los ciudadanos y la implicación de los profesionales sanitarios que han de desarrollar y evaluar una buena parte de los objetivos priorizados. 


\subsubsection{EL PROCESO DE ELABORACIÓN DEL PLA DE SALUT}

Planificar con una visión centrada en la salud, lo que actualmente se conoce como planificación para la salud, significó una nueva orientación en la tradición de planificación sanitaria en Catalunya. La elaboración del primer Pla de salut comportó también, una nueva metodología de trabajo, en un momento de transformación del modelo sanitario catalán. El período del segundo Pla de salut, manteniendo la coherencia con el primero, se enmarca en el contexto actual con un entorno organizativo más desarrollado y con nuevos elementos de referencia, lo que ha proporcionado más calidad al mismo proceso de elaboración.

Una de las características de este proceso de planificación es su elaboración desde el territorio - Regiones Sanitarias_- con la finalidad de asegurar un Pla de salut que integre todos aquellos elementos comunes a todas las regiones sanitarias y unos planes de salud de regiones que reflejen las especificidades de cada territorio.

El proceso de formulación del Pla de salut de Catalunya por parte del Servei Català de la Salut continua con la presentación del anteproyecto del Plan al Consell de Direcció y al Consell Català de la Salut del Servei Català de la Salut. Finalmente, el Departament de Sanitat i Seguretat Social lleva, para su aprobación definitiva, la propuesta de Pla de salut de Catalunya al Gobierno de la Generalitat, el cuál posteriormente lo presenta al Parlament de Catalunya.

\subsubsection{DISEÑO Y PLANIFICACIÓN DEL PROCESO DE ELABORACIÓN DEL PLA DE SALUT}

Siendo un proceso que se lleva de forma descentralizada, donde participa un número importante de personas y donde se ha de asegurar la coherencia y la calidad, el diseño no es una fase esencial para explicitar los criterios de calidad y sirve como instrumento de consenso y comunicación entre los equipos responsables de la elaboración, los diversos participantes, las estructuras directivas y los órganos de participación y de dirección del Servei Català de la Salut y del Departament de Sanitat i Seguretat Social. 


\subsubsection{CRITERIOS DE CALIDAD PARA LA ELABORACIÓN DEL PLA DE SALUT}

Contenido :

- Continuidad y coherencia con los planteamientos, los objetivos y las acciones de los anteriores planes de salud.

- Mantenimiento y mejoría de la salud y de la calidad de vida.

- Expresión de las diferencias entre territorios y entre grupos de población.

- Incorporación de nuevas prioridades.

- Desarrollo de estrategias orientadas a obtener ganancias en salud.

- Continuar impulsando la promoción de la salud y la prevención de la enfermedad.

- Equidad y adecuación de los servicios a las necesidades de la población.

- Mejoría de la calidad y la eficiencia del proceso de atención.

- Equilibrio prevención—asistencia—rehabilitación.

- Consenso de criterios clínicos para la atención a los problemas de salud.

- El usuario es una prioridad del sistema sanitario.

- Visión plural: participación y intersectorialidad.

- Intervenciones basadas en la evidencia científica.

- Explicitación de las estrategias para desarrollar las políticas de salud y de servicios.

Proceso de elaboración:

- Compromiso institucional.

- Descentralización.

- Participación.

- Intersectorialidad.

- Actualización de la información y análisis de las tendencias.

- Identificación de problemas según la importancia-morbididad, mortalidad, discapacidades, coste, impacto percibido-.

- Incorporación de los resultados de la evaluación de los períodos anteriores.

- Definición de las intervenciones según criterios de eficacia probada, factibilidad y aceptabilidad.

- Evaluación de las intervenciones.

7 Siguiendo parcialmente los criterios de calidad del Pla de salut de Catalunya 1996-1998 [1997, p. 28]. 
FIGURA 5.11. Elementos de referencia para la elaboración de los planes de salud.

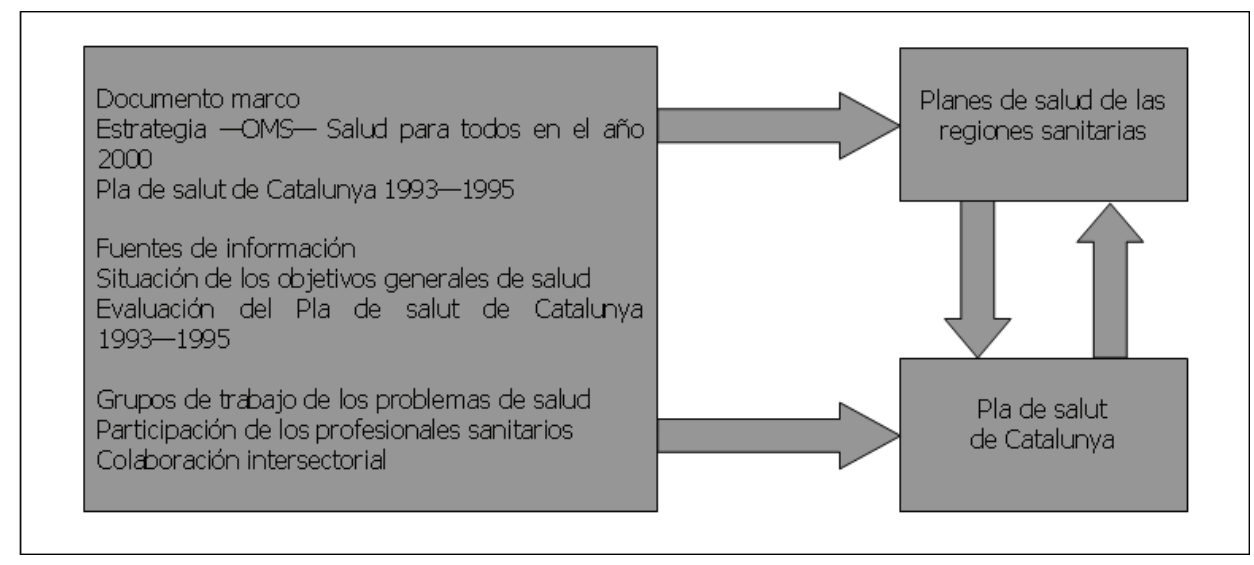

(C) Pla de salut de Catalunya 1996_-1998 [1997, p. 29].

El contenido de las actuaciones del Pla de salut se articula entorno a los problemas de salud identificados y la satisfacción de los ciudadanos. Los servicios sanitarios y sociosanitarios son los principales ámbitos, aunque no los únicos, donde se ejecutan las acciones propuestas por el Plan y desde donde se puede dar respuesta a las necesidades de salud, por lo que se debe proponer acciones sobre los servicios dirigidas a mejorar la gestión clínica del proceso de atención, la continuidad, la cooperación entre niveles, la eficacia y la eficiencia y plantear nuevas alternativas asistenciales en relación con los problemas de salud de la población.

Las propuestas que afectan los servicios se han centrado, de un lado, en acciones relacionadas directamente con los diversos problemas de salud y, del otro, las más generales, en un nuevo capítulo del Pla de salut donde se señalan las estrategias para desarrollar las políticas de salud y de servicios.

Orientar los servicios de acuerdo con la política de salud es una de las estrategias que, juntamente con las otras -implicar los profesionales, conocer y evaluar, implicar los ciudadanos y cooperar intersectorialmente-, han de permitir dirigir el conjunto de las acciones del sistema sanitario en la conquista de los objetivos del Pla de salut.

La gestión del proceso estuvo a cargo de la Unitat de Pla de Salut i Avaluació de l'Àrea Sanitària del Servei Català de la Salut, responsable de la elaboración del Pla de salut de Catalunya y de la coordinación del proceso. Las unidades de planificación de las regiones sanitarias son las responsables de la elaboración 
de los anteproyectos de Pla de salut de las regiones y su adaptación al Pla de salut de Catalunya.

Las diferentes fases del proceso se realizan sobre la base de un trabajo matricial entre los equipos citados y diferentes grupos de trabajo, con el soporte técnico de las diversas unidades del Servei Català de la Salut, del Departament de Sanitat i Seguretat Social y de las entidades y las instituciones con responsabilidad sobre la salud que participan. 
